Research Paper

\title{
Integrin $\alpha_{v} \beta_{3}-$ Targeted Radiotracer ${ }^{99 \mathrm{~m}}$ Tc-3P-RGD 2 Useful for Noninvasive Monitoring of Breast Tumor Response to Antiangiogenic Linifanib Therapy but not Anti-Integrin $\alpha_{v} \beta_{3} R \mathrm{RD}_{2}$ Therapy
}

\author{
Shundong Ji1, Yumin Zheng ${ }^{1,2}$, Guoqiang Shao', Yang Zhou ${ }^{1}$ and Shuang Liu ${ }^{\circledR}$ \\ 1. School of Health Sciences, Purdue University, IN 47907, USA. \\ 2. Department of Nuclear Medicine, China-Japan Friendship Hospital, Beijing, 100029, China.
}

$\triangle$ Corresponding author: Dr. Shuang Liu, School of Health Sciences, Purdue University, 550 Stadium Mall Drive, West Lafayette, Indiana 47907. Phone: 765-494-0236; Fax 765-496-1377; Email: liu100@.purdue.edu.

() Ivyspring International Publisher. This is an open-access article distributed under the terms of the Creative Commons License (http://creativecommons.org/ licenses/by-nc-nd/3.0/). Reproduction is permitted for personal, noncommercial use, provided that the article is in whole, unmodified, and properly cited.

Received: 2013.06.24; Accepted: 2013.08.06; Published: 2013.10.12

\begin{abstract}
Purpose: ${ }^{99 m T c-3 P-R G D} 2$ is a $99 \mathrm{mTc}$-labeled dimeric cyclic RGD peptide that binds to integrin $\alpha_{\mathrm{v}} \beta_{3}$ with high affinity and specificity. The purpose of this study was to demonstrate the utility of $99 \mathrm{mTC}-3 \mathrm{P}-\mathrm{RGD}_{2}$ SPECT/CT (single photon emission computed tomography/computed tomography) as a molecular imaging tool for noninvasive monitoring breast tumor early response to antiangiogenesis therapy with linifanib, and to illustrate its limitations in monitoring the efficacy of anti- $\alpha_{v} \beta_{3}$ treatment.

Methods: To support SPECT/CT imaging, biodistribution and therapy studies, the xenografted breast cancer model was established by subcutaneous injection of $5 \times 10^{6}$ MDA-MB-435 cells into the fat pad of each athymic nude mouse. Linifanib (ABT-869) was used as antiangiogenesis agent. The tumor volume was $180 \pm 90 \mathrm{~mm}^{3}$ on the day (-I day) before baseline SPECT/CT. Each animal was treated twice daily with vehicle or $12.5 \mathrm{mg} / \mathrm{kg}$ linifanib. Longitudinal $99 \mathrm{mTC}-3 \mathrm{P}-\mathrm{RGD}_{2}$ SPECT/CT imaging was performed on days - I, I, 4 and II. Tumors were harvested at each time point for pathological analysis of hematoxylin and eosin (H\&E) and immunohistochemistry (IHC). Tumor uptake of 99mTc-3P-RGD 2 was calculated from SPECT/CT quantification. When cyclic peptide $E[c(R G D f K)]_{2}\left(R G D_{2}\right)$ was used as the anti- $\alpha_{v} \beta_{3}$ agent, SPECT/CT images were obtained only at 7 and 21 days after last $R G D_{2}$ dose.

Results: The tumor uptake of $99 \mathrm{mTc}-3 \mathrm{P}-\mathrm{RGD}_{2}$ from SPECT/CT quantification was almost identical to that from biodistribution. There was a dramatic reduction in both \%ID and \%ID/cm ${ }^{3}$ tumor uptake of $99 \mathrm{mTc}-3 \mathrm{P}-\mathrm{RGD}_{2}$ during the first 24 hours of linifanib therapy. The therapeutic effect of linifanib was on both tumor cells and vasculature, as determined by IHC analysis of integrin $\alpha_{\mathrm{v}} \beta_{3}$ and $C D 3 \mathrm{I}$. Changes in tumor vasculature were further confirmed by pathological $\mathrm{H} \& \mathrm{E}$ analysis of tumor tissues. While its \%ID tumor uptake increased steadily in vehicle-treated group, the \%ID tumor uptake of 99mTc-3P-RGD 2 decreased in linifanib-treated group slowly over the II-day study period. The degree of tumor response to linifanib therapy correlated well to the integrin $\alpha_{v} \beta_{3}$ expression levels before linifanib therapy.

Conclusion: ${ }^{99 m T c}-3 \mathrm{P}-\mathrm{RGD}_{2}$ is an excellent radiotracer for monitoring integrin $\alpha_{\mathrm{v}} \beta_{3}$ expression during and after linifanib therapy. ${ }^{99 m T C-3 P-R G D} 2$ SPECT/CT is an useful molecular imaging tool for patient selection before antiangiogenic and anti- $\alpha_{v} \beta_{3}$ therapy; but it would be difficult to use $99 \mathrm{mT}$ T- $3 P-R G D_{2}$ for accurate and noninvasive monitoring of early tumor response to anti- $\alpha_{v} \beta_{3}$ therapy.
\end{abstract}

Key words: Linifanib, monitoring antiangiogenic therapy, integrin $\mathrm{a}_{\mathrm{v}} \beta_{3}$, and ${ }^{99 m T c-3 P-R G D}$.

\section{Introduction}

Solid tumor cells require higher levels of oxygen and metabolites to support their rapid uncontrolled growth than normal cells [1-5]. This is accomplished by increased angiogenesis at tumor site and is often 
seen as the rate limiting step in tumor progression [3, 5]. Targeting tumor angiogenesis with small molecular inhibitors represents a promising strategy for controlling and eradicating tumor growth [6-8]. Linifanib (ABT-869) is a multi-targeted receptor tyrosine kinase inhibitor, specifically targeting vascular endothelial growth factor (VEGF) and platelet-derived growth factor (PDGF) receptors [9-14]. In vitro, linifanib was shown to inhibit the phosphorylation of members of VEGF and PDGF receptor families [11]. Treatment with linifanib resulted in pronounced regression of tumors in vivo in a variety of pre-clinical tumor models [12-14]. Clinical studies showed promising results in breast cancer, metastatic non-small cell lung cancer (NSCLC), and liver cancer $[15,16]$. As antiangiogenic therapies have become more common, finding suitable translational biomarkers for antiangiogenic modulation of the tumor vasculature has become critically important.

Microvessel density (MVD) has been proposed as a prognostic indicator of progression, overall survival, and disease-free survival in cancer patients [17, 18]. Evaluation of MVD is typically performed by immunostaining endothelial cells in tumor tissues and counting the number of vessels using a high power field microscope. This approach is not practical for routine monitoring of antiangiogenic therapy due to its invasive nature. DCE (dynamic contrast-enhanced) MRI (magnetic resonance imaging) has been used to measure tumor perfusion properties [19-22], but DCE-MRI is technically challenging and standardization is complicated. $\left[{ }^{18} \mathrm{~F}\right] \mathrm{FDG}$ PET was used to monitor linifanib therapy by determining reduced metabolic activity in the "treated" tumors [13], but glucose metabolism may not be an ideal biomarker for monitoring antiangiogenic therapy because most of metabolic activities take place in tumor cells rather than tumor vasculature.

Altered integrin $\alpha_{\mathrm{v}} \beta_{3}$ expression has been detected in carcinomas of breast [23-25], prostate [26], ovary [27], lung [28], melanomas [29], and gliomas $[30,31]$. The integrin $\alpha_{v} \beta_{3}$ expression has been correlated with an aggressive phenotype and metastatic dissemination [32-35]. It was reported that the integrin $\alpha_{\mathrm{v}} \beta_{3}$ is overexpressed on both tumor cells and neovasculature in breast cancer xenografts [36], and is an interesting target to develop new imaging probes for early cancer detection [37-39]. It is well-established that the cross-talk between integrins and receptor tyrosine kinases (e.g. VEGFR and PDGFR) is crucial for many cellular functions [40-42]. Integrin $\alpha_{v} \beta_{3}$ and PDGFR- $\beta$ co-precipitate and PDGFR activation increases endothelial cell migration and preliferation. The functional association between VEGFR2/PDGFR and integrin $\alpha_{v} \beta_{3}$ is of reciprocal nature since each is able to promote activation of its counterpart. This mutually beneficial relationship provides the conceptual basis to use radiolabeled cyclic RGD peptides as radiotracers for tumor imaging [43-52] and noninvasive monitoring of anti- $\alpha_{v} \beta_{3}$ and antiangiogenesis therapy $[52,53]$. While they are appreciated for their role as noninvasive tools to monitor tumor response to antiangiogenesis therapy [43-46], it remains untested if integrin $\alpha_{v} \beta_{3}$-targeted radiotracers are useful for monitoring the tumor response to anti- $\alpha_{\mathrm{v}} \beta_{3}$ treatment.

In this study, we evaluated ${ }^{99 m} \mathrm{Tc}-3 \mathrm{P}-\mathrm{RGD}_{2}$, a 99mTc-labeled cyclic RGD peptide dimer [54, 55], for its capability to monitor integrin $\alpha_{v} \beta_{3}$ expression during breast tumor growth and after treatment with linifanib and $E[c(R G D f K)]_{2}\left(R_{G D}\right)$ in the xenografted MDA-MB-435 human breast tumor model. ${ }^{99 m}$ Tc-3P-RGD 2 is of our particular interest due to the linear relationship between its tumor uptake and integrin $\alpha_{v} \beta_{3}$ expression [56]. ${ }^{99 \mathrm{~m} T c-3 P-R G D}{ }_{2}$ SPECT/CT has been successfully used for quantification of radioactivity accumulation, delineation of tumor necrosis [57], and monitoring progression of breast cancer lung metastases [58]. $\mathrm{RGD}_{2}$ was used as anti- $\alpha_{v} \beta_{3}$ agent due to its higher integrin $\alpha_{\mathrm{v}} \beta_{3}$ binding affinity than that of c(RGDfK) because of dimerization [54]. MDA-MB-435 cell line was of interest due to its high potential for metastasis. Despite the controversy associated with its identity [59-61], more recent results confirmed that MDA-MB-435 is indeed a poorly differentiated and aggressive breast tumor cell line [62]. The main objective of this study was to demonstrate the utility of 99mTc-3P-RGD ${ }_{2}$ SPECT/CT as a molecular imaging tool for monitoring early tumor response to antiangiogenesis therapy in small animals, and to illustrate its limitations in monitoring the efficacy of anti- $\alpha_{v} \beta_{3}$ treatment.

\section{MATERIALS AND METHODS}

Chemicals and Analytical Method. Linifanib (ABT-869) was from AbbVie Inc. (North Chicago, IL). Trisodium triphenylphosphine-3,3',3"-trisulfonate (TPPTS) and tricine were purchased from Sigma-Aldrich (St. Louis, Missouri), and were used without further purification. Cyclic RGD peptides, $\mathrm{E}[\mathrm{c}(\mathrm{RGDfK})]_{2} \quad\left(\mathrm{RGD}_{2}\right)$ and $\mathrm{PEG}_{4}-\mathrm{E}\left[\mathrm{PEG}_{4}{ }^{-}\right.$ $\mathrm{c}(\mathrm{RGDfK})]_{2}$ (3P-RGD ${ }_{2}: \mathrm{PEG}_{4}=15$-amino-4,7,10,13tetraoxapentadecanoic acid), were made by Peptides International Inc. (Louisville, KY). HYNIC-3P-RGD 2 (HYNIC = 6-(2-(2-sulfonatobenzaldehyde)hydrazono )nicotinyl) was prepared using the method described in our previous communication [55]. $\mathrm{Na}^{99} \mathrm{mcO}_{4}$ was obtained from Cardinal HealthCare (Chicago, IL). The radio-HPLC method used a LabAlliance system 
equipped with a $\beta$-ram IN-US detector and Zorbax $C_{18}$ column (4.6 mm x $250 \mathrm{~mm}, 300 \AA$ A pore size; Agilent Technologies, Santa Clara, CA). The flow rate was 1 $\mathrm{mL} / \mathrm{min}$. The mobile phase was isocratic with $90 \%$ solvent $\mathrm{A}\left(25 \mathrm{mM} \mathrm{NH}_{4} \mathrm{OAc}\right.$ buffer, $\left.\mathrm{pH}=5.0\right)$ and $10 \%$ solvent $\mathrm{B}$ (acetonitrile) at $0-5 \mathrm{~min}$, followed by a gradient mobile phase from $10 \% \mathrm{~B}$ at $5 \mathrm{~min}$ to $40 \% \mathrm{~B}$ at $20 \mathrm{~min}$.

Radiolabeling and Dose Preparation. 99mTc-3P-RGD 2 was prepared according to the literature method [55] using lyophilized kit formulation containing $20 \mu \mathrm{g}$ HYNIC-3P-RGD $2,5 \mathrm{mg}$ TPPTS, 6.5 $\mathrm{mg}$ tricine, $40 \mathrm{mg}$ mannitol, $38.5 \mathrm{mg}$ disodium succinate hexahydrate and $12.7 \mathrm{mg}$ succinic acid. 99mTc-labeling was accomplished by adding $\sim 1.5 \mathrm{~mL}$ of $\mathrm{Na}^{99 \mathrm{mTCO}_{4}}$ solution $(1,110-1,850 \mathrm{MBq})$. The reconstituted vial was heated in a $100{ }^{\circ} \mathrm{C}$ water bath for $20-30$ min. Radiochemical purity determined by radio-HPLC must be $>95 \%$ before being used for both imaging and biodistribution studies. Doses for biodistribution were prepared by dissolving the radiotracer in saline to a concentration of $\sim 1.1 \mathrm{MBq} / \mathrm{mL}$. For SPECT/CT imaging, doses were prepared by dissolving the radiotracer in saline to a concentration of $370-740 \mathrm{MBq} / \mathrm{mL}$. The dose solution was filtered with a $0.20 \mu \mathrm{m}$ Millex-LG filter before being injected into animals. Each animal was injected with $0.1-0.2$ $\mathrm{mL}$ of the dose solution.

Cell Culture. MDA-MB-435 cell line was obtained from ATCC (American Type Culture Collection, Manassas, VA). Tumor cells were grown at $37^{\circ} \mathrm{C}$ in Minimal Essential Medium (Alpha Modification) supplemented with $10 \%$ fetal bovine serum (FBS, ATCC) and 1\% penicillin and streptomycin solution (GIBCO Industries Inc., Langley, OK), and at $37^{\circ} \mathrm{C}$ in a humidified atmosphere of $5 \% \mathrm{CO}_{2}$ in air. Cells were grown as monolayers and were harvested or split when they reached $90 \%$ confluence to maintain exponential growth.

Animal Model. Biodistribution and imaging studies were performed using athymic nude mice bearing MDA-MB-435 breast cancer xenografts in compliance NIH animal experiment guidelines (Principles of Laboratory Animal Care, NIH Publication No. 86-23, revised 1985). The protocol for animal studies has been approved by the Purdue University Animal Care and Use Committee (PACUC). Female athymic $\mathrm{nu} / \mathrm{nu}$ mice were purchased from Harlan (Indianapolis, IN) at $4-5$ weeks of age. Each animal implanted with $5 \times 10^{6}$ MDA-MB-435 cells into the fat pad. The tumor volume was measured every two days for the first two weeks, every day for next 3 weeks, and calculated by the formula: (length $\times$ width $\left.^{2}\right) / 2$. Animals were subjected to biodistribution and imaging at specified times.
Linifanib Treatment Protocol. Groups $(n=5)$ were size-matched with an average tumor volume of $180 \pm 90 \mathrm{~mm}^{3}$ one day before baseline SPECT/CT imaging. Vehicle $(0.15 \%$ hydroxypropylmethyl cellulose, 2\% ethanol, 5\% Tween 80, 20\% PEG400, 73\% saline) or linifanib treatment was initiated at a dose of $12.5 \mathrm{mg} / \mathrm{kg}$ on day 0 after baseline imaging. Linifanib was dosed orally twice daily, with a time interval of $>8 \mathrm{~h}$ between consecutive doses.

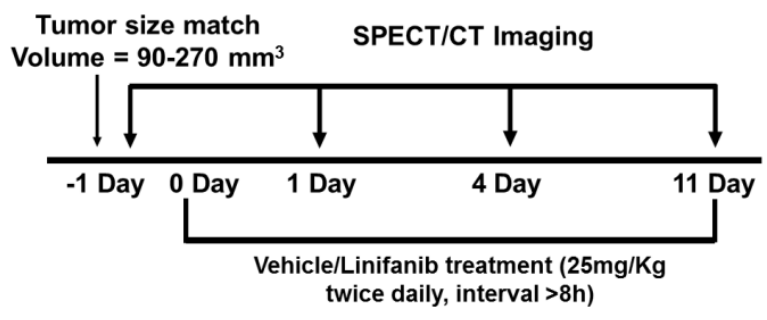

Imaging Protocol for SPECT/CT. Longitudinal SPECT/CT imaging was performed at $-1,1,4$ and 11 days after initiation of linifanib treatment using a u-SPECT-II/CT scanner (Milabs, Utrecht, The Netherlands) equipped with $0.6 \mathrm{~mm}$ multi-pinhole collimators. Linifanib was dosed two hours prior to SPECT/CT. One hour before SPECT/CT imaging, 99mTc-3P-RGD 2 (37 - 55.5 MBq) was administered via the lateral tail vein. Anesthesia was induced using an air flow rate of $350 \mathrm{~mL} / \mathrm{min}$ and approximately $3.0 \%$ isoflurane. After induction of anesthesia, the air flow rate was reduced to $250 \mathrm{~mL} / \mathrm{min}$ with approximately $2.0 \%$ isoflurane. SPECT images were acquired using 75 projections over 30 minutes. After SPECT acquisition, CT imaging was performed using 'normal' acquisition settings (2 degree intervals) at $45 \mathrm{kV}$ and 500 $\mu \mathrm{A}$. SPECT reconstruction, data processing and quantification of organ uptake were performed according to literature methods [56, 57]. Reconstructed images were visualized as both orthogonal slices and maximum intensity projections. The tumor uptake of ${ }^{99 m}$ Tc-3P-RGD 2 was reported as the percentage of injected dose (\%ID) and percentage of injected dose per unit volume $\left(\% \mathrm{ID} / \mathrm{cm}^{3}\right)$, and was compared with that obtained from biodistribution.

$\mathbf{R G D}_{2}$ Treatment Protocol. Each mouse was implanted subcutaneously with $5 \times 10^{6}$ MDA-MB-435 cells into the fat pads. Seven days after inoculation of MDA-MB-435 cells, the tumor-bearing mice were randomly divided into 2 groups: the vehicle-treated group $(n=5)$ and $R_{G D}$-treated group $(n=5)$ administered intravenously by tail-vein injection of $\mathrm{RGD}_{2}$ at a dose of $50 \mathrm{mg} / \mathrm{kg}$. The $\mathrm{RGD}_{2}$-treatment was continued for 10 days (a dose every two days with a total of 5 doses). Animals in the vehicle-treated group were administered with equal volume of saline. SPECT/CT imaging was performed at week 1 or week 3 after the 
final dose of $\mathrm{RGD}_{2}$ treatment. Quantification of organ uptake and tumor-to-background ratios were performed according to the methods described in our previous reports [56, 57]. Muscle was used as background. The region fo interest (ROI $\sim 0.01 \mathrm{~cm}^{3}$ ) was drawn over the contralateral forelimb. Tumor/muscle $(\mathrm{T} / \mathrm{M})$ ratios were calculated on the basis of $\% \mathrm{ID} / \mathrm{cm}^{3}$ uptake values of ${ }^{99 \mathrm{~m}} \mathrm{Tc}-3 \mathrm{P}-\mathrm{RGD}_{2}$ in tumor and muscle of the same animal, and were reported as the means \pm the standard deviation.

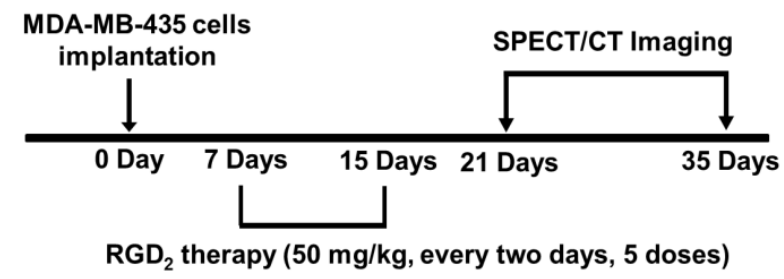

Biodistribution Protocol. The tumor-bearing mice (tumor sizes $=0.05-1.5 \mathrm{~g}$ ) were used for biodistribution studies. Each animal $(20-25$ g) was administered with $\sim 110 \mathrm{kBq}$ of $99 \mathrm{mTc}-3 \mathrm{P}-\mathrm{RGD}_{2}$ by tail vein injection. Animals were sacrificed by sodium pentobarbital overdose $(\sim 200 \mathrm{mg} / \mathrm{kg})$ at $60 \mathrm{~min}$ post-injection (p.i.). Blood was withdrawn from the heart of tumor-bearing mice. Tumors and normal organs (brain, eyes, heart, spleen, lungs, liver, kidneys, muscle and intestine) were harvested, washed with saline, dried with absorbent tissue, weighed, and counted on a Perkin Elmer Wizard - $1480 \gamma$-counter (Shelton, CT). The organ uptake was calculated as the percentage of injected dose (\%ID) and percentage of injected dose per gram of tissue (\%ID/g).

Tumor Immunohistochemistry. Tumor tissues were harvested from animals, and were snap-frozen in the OCT (optical cutting temperature) solution (Sakara, Torrance, CA). Tumor tissues were then cut into slices $(5 \mu \mathrm{m})$. After drying at room temperature, slices were fixed with ice-cold acetone for $10 \mathrm{~min}$, and dried in air for $20 \mathrm{~min}$ at room temperature. Sections were blocked with $10 \%$ goat serum for $30 \mathrm{~min}$ at room temperature, and then were incubated with the hamster anti-integrin $\beta_{3}$ antibody (1:100, BD Biosciences, San Jose, CA) and rat anti-CD31 antibody (1:100, V:V; BD Biosciences) for $1 \mathrm{~h}$. After incubating with Cy3-conjugated goat anti-hamster and FITC-conjugated goat anti-rat secondary antibodies (1:100, Jackson ImmunoResearch Inc., West Grove, PA) and washing with PBS, the fluorescence was visualized with a Nikon fluorescence microscope. All pictures were taken under 200x magnification with the same exposure time.

Statistical Analysis. All data were expressed as means plus/minus standard deviation based on results from five animals. Statistical analysis was per- formed by one-way analysis of variance (ANOVA) followed by the Newman-Keuls test. The level of significance was set at $p<0.05$. GraphPad Prism 5 (GraphPad Software Inc., La Jolla, CA) was used for linear and nonlinear regression analysis.

\section{RESULTS}

Monitoring of Breast Tumor Growth. Figure 1A shows 3D and transverse views of SPECT/CT images of a tumor-bearing mouse at 5, 7, 14, 21, 28 and 35 days after inoculation of MDA-MB-435 breast tumor cells. Small tumors (Figure 1A: D5) was readily detected with excellent contrast. When the tumor size was $0.15-0.40 \mathrm{~cm}^{3}$, the radioactivity distribution was relatively uniform. After week 3, the tumors were $>0.50 \mathrm{~cm}^{3}$, and the radioactivity distribution heterogeneity was significant due to tumor necrosis (Figure 1A: D28). By week 5, there was extensive necrosis in MDA-MB-435 breast tumors. Necrotic regions had little radioactivity accumulation (Figure 1A: D28 D35) due to lack of integrin $\alpha_{v} \beta_{3}$ expression (Figure 1B).

Comparison of Breast Tumor Uptake Values from SPECT/CT and Biodistribution. To validate u-SPECT-II/CT as a tool for quantification of the tumor uptake of ${ }^{99 \mathrm{mTC}} \mathrm{TP}-\mathrm{RGD}_{2}$, we performed a biodistribution study using animals with tumor size being $0.01-1.2 \mathrm{~g}$, and compared the tumor uptake values to those from SPECT/CT quantification. Figure 2 exhibits the relationship between the tumor size $\left(\mathrm{cm}^{3}\right)$ and the tumor uptake (\%/ID for total radioactivity and $\% / \mathrm{ID} / \mathrm{g}$ or $\% / \mathrm{ID} / \mathrm{cm}^{3}$ for radioactivity concentration) determined by SPECT/CT (A and C) and biodistribution (B and D). Apparently, the tumor up-

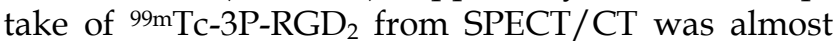
identical to that from biodistribution. Similar results were also seen in the U87MG model [64]. $\mathrm{u}$-SPECT-II/CT is excellent imaging platform for accurate quantification of tumor uptake of 99mTc-3P-RGD 2 in small animals.

Tumor Uptake Changes during Tumor Growth. When the tumors were very small $\left(<0.1 \mathrm{~cm}^{3}\right)$, their uptake of $99 \mathrm{mTc}-3 \mathrm{P}-\mathrm{RGD}_{2}$ were low due to lack of integrin $\alpha_{v} \beta_{3}$ contribution from neovasculature. Between weeks 2 and 3, the tumor size was in the range of $0.15-0.30 \mathrm{~cm}^{3}$, and the \%ID/g tumor uptake of 99mTc-3P-RGD 2 peaked (Figure 2: B and D). Between weeks 4 and 5 , the tumor size was $>0.5 \mathrm{~cm}^{3}$. During this period, the \% ID tumor uptake of $99 \mathrm{mTc}-3 \mathrm{P}-\mathrm{RGD}_{2}$ was enhanced steadily with increased tumor size (Figure 2: A and C), but its \% ID/g uptake decreased slowly due to necrosis (Figure 1B), maturation of blood vessels, and larger interstitial space [63]. The overall relationship between tumor volume and \% ID uptake of ${ }^{99 m T c}-3 P-R G D_{2}$ was linear (Figure 2: $A: R^{2}=$ 
0.923; and $\left.\mathrm{C}: \mathrm{R}^{2}=0.859\right)$. The relationship between tumor size and $\% \mathrm{ID} / \mathrm{cm}^{3}$ tumor uptake of
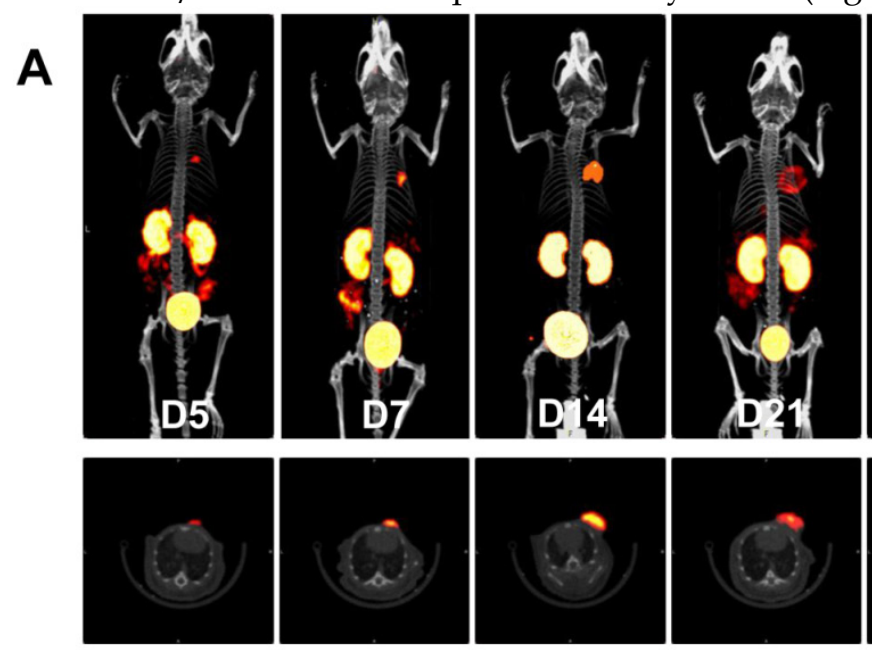

CD31

B
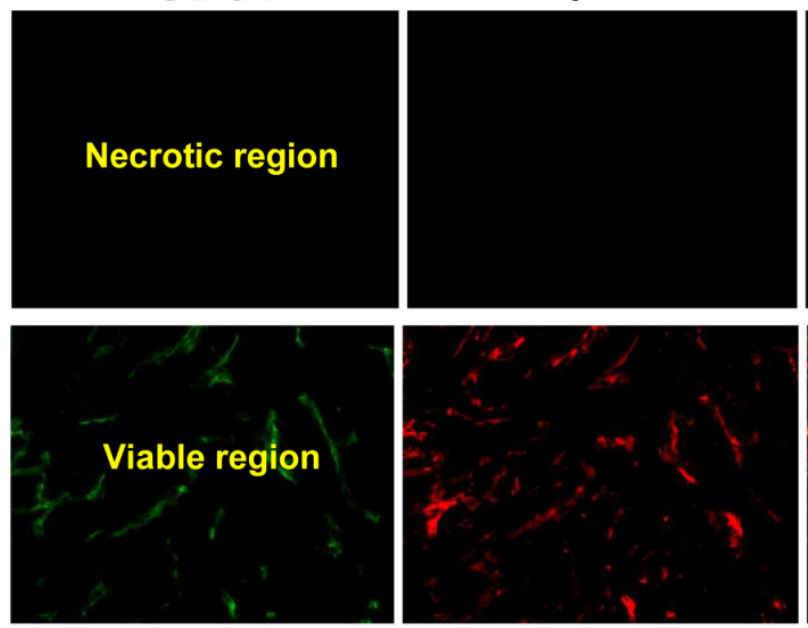

$\beta_{3}$
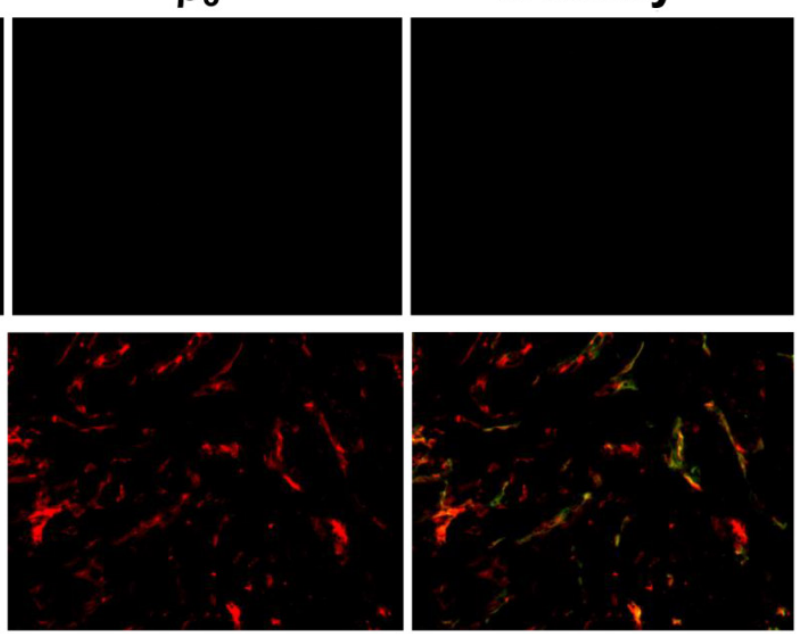

Fig I. A: The 3D (upper panel) and transverse (lower panel) views of SPECT/CT images of a mouse with bearing MDA-MB-435 breast cancer xenografts at 5, 7, I4, 2 I, 28 and 35 days after inoculation of MDA-MB-435 human breast cancer cells. The animal was administered with $37-55.5$ MBq of $99 \mathrm{mTc}-3 \mathrm{P}-\mathrm{RGD} 2$ via the lateral tail vein. B: Microscopic images (Original magnification: $\times 200$ ) of tumor slice selected from the necrotic and viable regions after immunohistochemical staining for integrin $\beta_{3}$ and CD3I. The tumor tissue was harvested on day 28 days after inoculation of MDA-MB-435 cells. CD3I was used as a biomarker for endothelial cells on blood vessels (both mature vasculature and neovasculture). Integrin $\beta_{3}$ was visualized with Cy3 (red) and CD3I was visualized with FITC (green). The yellow color in overlay images indicates the presence of integrin $\beta_{3}$ on neovasculature.

Fig 2. Left: Linear relationship between the tumor size $\left(\mathrm{cm}^{3}\right)$ and the tumor uptake (\%/ID for total radioactivity accumulation) determined by SPECT/CT quantification $(\mathbf{A})$ and biodistribution (C). Right: Relationship between the tumor size $(\mathrm{g})$ and tumor uptake $\left(\% / \mathrm{ID} / \mathrm{g}\right.$ or $\% / \mathrm{ID} / \mathrm{cm}^{3}$ for radioactivity concentration) obtained from SPECT/CT quantification (B) and biodistribution (D: $\mathrm{n}=26)$.
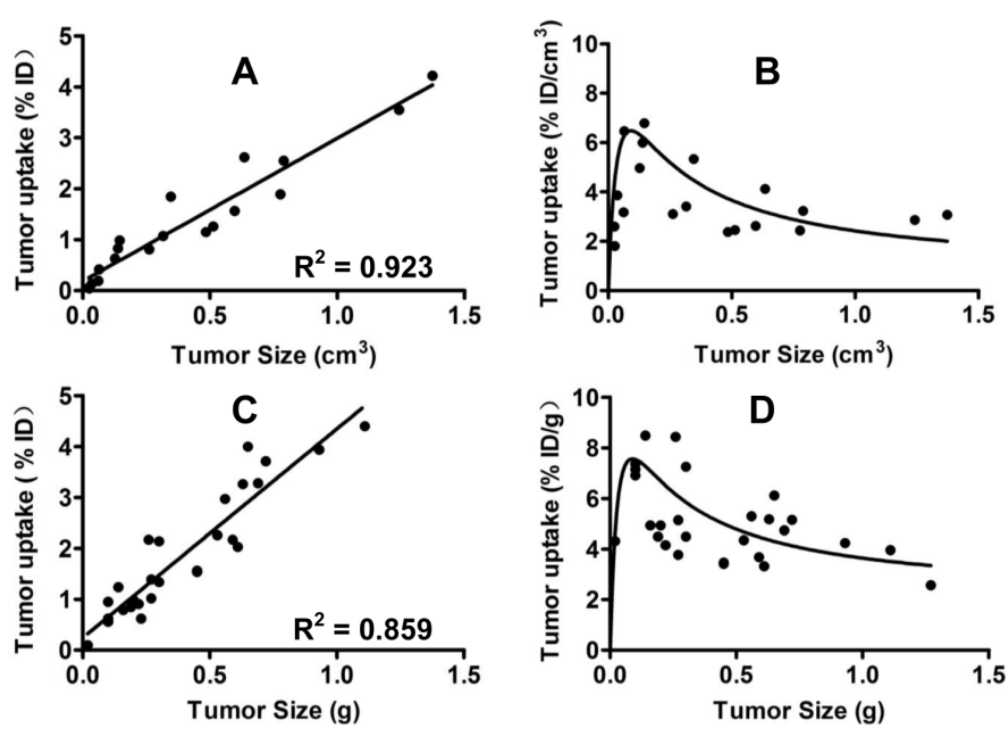
Integrin $\alpha_{v} \beta_{3}$ Expression Changes during Tumor Growth. Figure 3 displays selected microscopic images of the slices obtained from the xenografted MDA-MB-435 tumors $(0.05 \mathrm{~g}, 0.13 \mathrm{~g}, 0.28 \mathrm{~g}, 0.55 \mathrm{~g}$ and $0.88 \mathrm{~g}$ ) after immunohistochemical staining for integrin $\beta_{3}$ and CD31. As expected, small tumors $(<0.05 \mathrm{~g})$ had few microvessels with very little integrin $\alpha_{v} \beta_{3}$ expression. When tumors became larger $(0.2-0.5 \mathrm{~g})$, the blood vessel density was increased, as illustrated

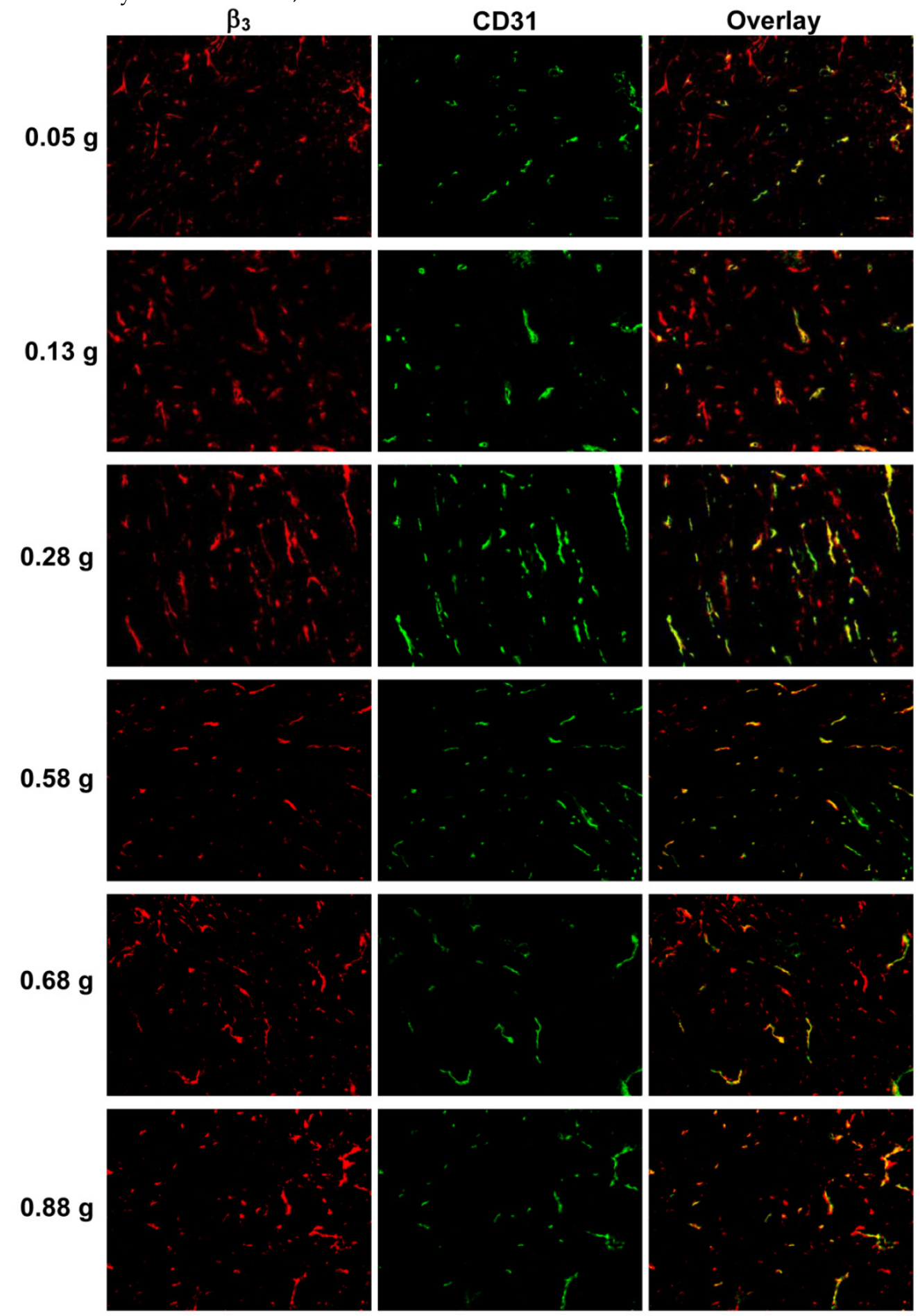

Fig 3. Microscopic images of frozen tumor slices from the xenografted MDA-MB-435 tumors $(0.05 \mathrm{~g}, 0.13 \mathrm{~g}, 0.28 \mathrm{~g}, 0.55 \mathrm{~g}$ and $0.88 \mathrm{~g})$ after immunohistochemical staining for integrin $\beta_{3}$ and CD3 I. CD3 I was used as a biomarker for tumor endothelial cells. Integrin $\beta_{3}$ was visualized with Cy3 (red), and CD3 I with FITC (green).

Yellow color indicates the integrin $\beta_{3}$ on new blood vessels. by the enhanced yellow and orange colors on overlay images. When tumors were $>0.5 \mathrm{~g}$, the tumor blood vessel density decreased while the total integrin $\alpha_{v} \beta_{3}$ expression level was increased due to more contributions from MDA-MB-435 tumor cells, which was completely consistent with the \%ID tumor uptake values of ${ }^{99 \mathrm{~m} T c}-3 \mathrm{P}-\mathrm{RGD}_{2}$ (Figure 2: B and D).

CD31 
Monitoring Tumor Response to Linifanib Therapy. Figure 4A compares tumor volume changes in both vehicle $(n=5)$ and linifanib $(n=5)$ treated groups. A significant difference in tumor volume (Figure 4A: $p<0.05$ ) was seen between vehicle and linifanib-treated groups after 4 days of linifanib treatment. This effect is further illustrated by SPECT/CT images (Figure 4B) obtained at -1, 1, 4 and 11 days after initiation of linifanib therapy. Figure 5 shows SPECT/CT quantification data to illustrate early breast tumor response to linifanib antiangio- genesis therapy. In the linifanib-treated group, there was a dramatic reduction in both \% ID and \% ID $/ \mathrm{cm}^{3}$

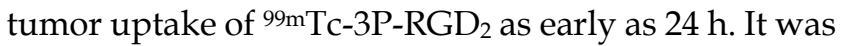

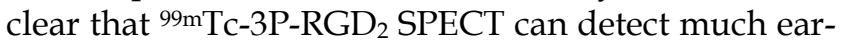
lier biological changes (decrease in integrin $\alpha_{v} \beta_{3}$ expression level) as a result of linifanib therapy. The

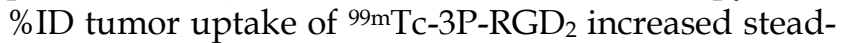
ily in the vehicle-treated group (Figure 5A), while its $\% \mathrm{ID} / \mathrm{cm}^{3}$ tumor uptake decreased slowly over 11 day study period (Figure 5B).

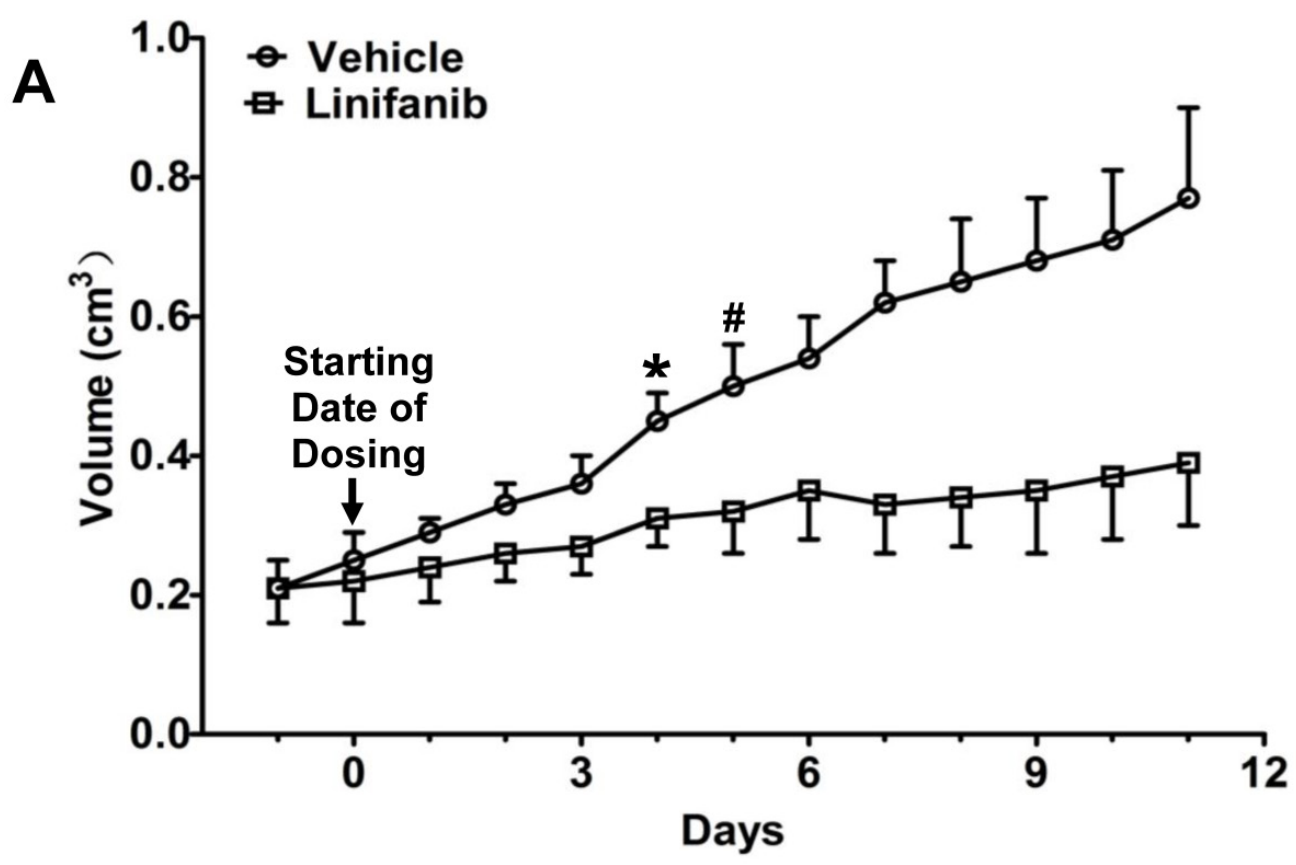

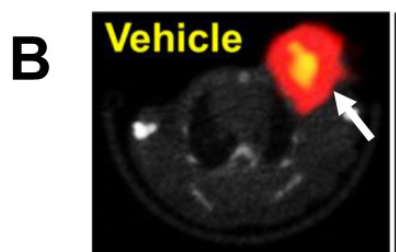

$-1 \mathrm{D}$

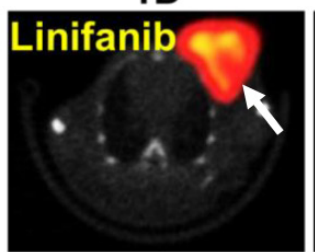

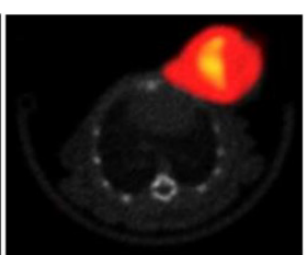

1D

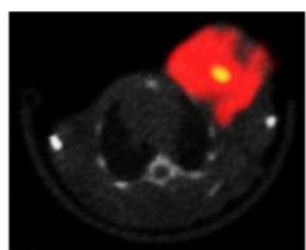

4D
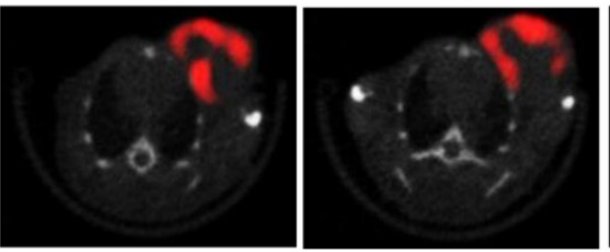

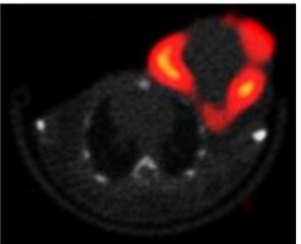

11D

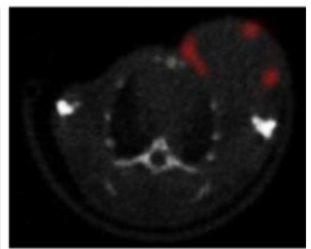

Fig 4. A: Comparison of tumor volumes in vehicle and linifanib-treated in the MDA-MB-435 models. Tumor volume was determined by caliper measurements. $*$ : $p$ $<0.05$, significantly different from the vehicle-treated group. \#: $p<0.01$, significantly different from the vehicle-treated group from that specific date until the end of study. B: Transverse views of selected SPECT/CT images from athymic nude mice bearing MDA-MB-435 breast tumors in the vehicle (upper panel) and linifanib-treated groups (lower panel). SPECT/CT images were obtained at -I, I, 4 and II days after initiation of linifanib therapy to illustrate the early tumor response in terms of tumor uptake and integrin $a_{v} \beta_{3}$ expression levels. Arrows indicate the presence of tumors. 

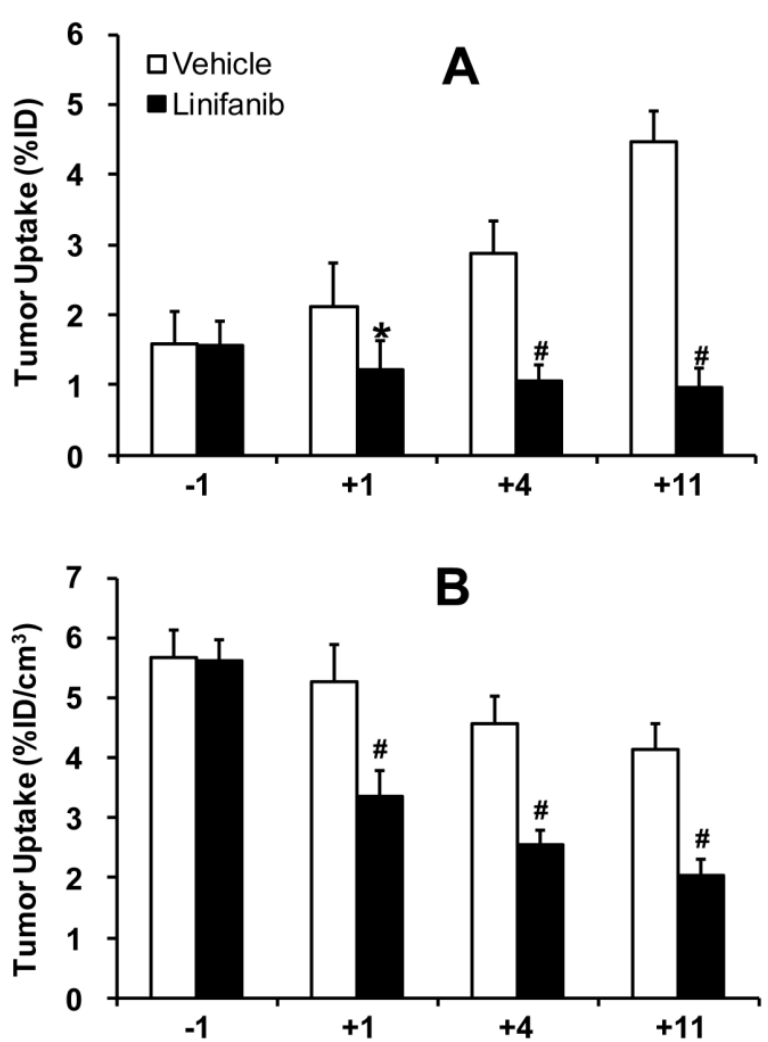

Fig 5. Direct comparison of the \%ID tumor uptake (top) and $\% 1 \mathrm{I} / \mathrm{cm}^{3}$ tumor uptake (bottom) of $99 \mathrm{mTc}-3 \mathrm{P}-\mathrm{RGD}_{2}$ in the vehicle $(n=5)$ and linifanib-treated $(n=5)$ groups. The tumor uptake values were calculated from quantification of SPECT/CT images. *: $p<0.05$, significantly different from the vehicle-treated group. \#: $p<0.0$ l, significantly different from the vehicle-treated group.

Comparison of Tumor Response in Different Animal Models. Figure 6 compares the changes in $\% \mathrm{ID} / \mathrm{cm}^{3}$ tumor uptake and $\mathrm{T} / \mathrm{M}$ ratios of 99mTc-3P-RGD 2 after linifanib treatment in three different xenografted tumor-bearing animal models (U87MG with high integrin $\alpha_{\mathrm{v}} \beta_{3}$ expression on tumor cells and tumor neovasculature; MDA-MB-435 with moderate integrin $\alpha_{\mathrm{v}} \beta_{3}$ expression on tumor cells and neovasculature; and PC-3 with low integrin $\alpha_{\mathrm{v}} \beta_{3}$ expression on tumor cells and neovasculature). The $\% \mathrm{ID} / \mathrm{cm}^{3}$ tumor uptake and $\mathrm{T} / \mathrm{M}$ ratios of 99mTc-3P-RGD 2 in U87MG glioma and PC-3 prostate models were obtained from our previous studies [64]. The degree of tumor response (Figure 6A: defined by the $\% \mathrm{ID} / \mathrm{cm}^{3}$ tumor uptake change of $99 \mathrm{mTc}-3 \mathrm{P}-\mathrm{RGD}_{2}$ ) to linifanib therapy was highest for U87MG gliomas, moderate for MDA-MB-435 breast tumors, and lowest for PC-3 prostate tumors. T/M ratio changes in the xenografted U87MG and MDA-MB-435 tumors were more significant than those in PC-3 tumors. There was no significant difference (Figure $6 \mathrm{~B}$ ) in $\mathrm{T} / \mathrm{M}$ ratio changes between the U87MG and MDA-MB-435 models within experiemtnal errors.
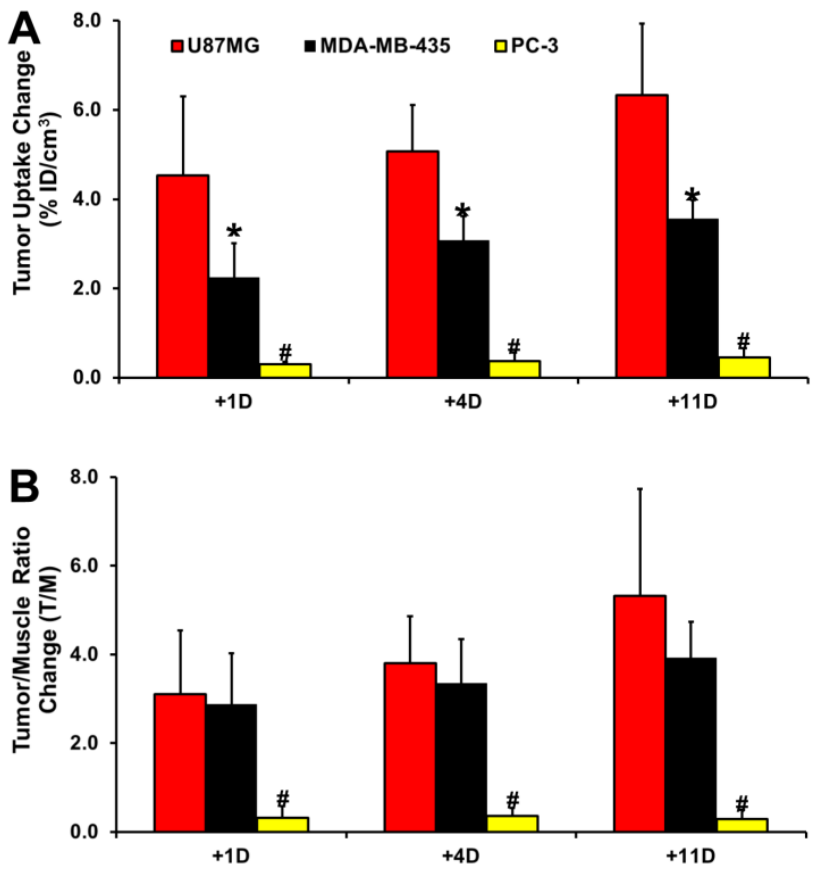

Fig 6. Comparison of changes in $\% \mathrm{ID} / \mathrm{cm}^{3}$ tumor uptake $(\mathbf{A})$ and $\mathrm{T} / \mathrm{M}$ ratios $(\mathbf{B})$ of $99 \mathrm{mTc}-3 \mathrm{P}-\mathrm{RGD}_{2}$ after linifanib treatment in three different tumor-bearing animal models (U87MG: high integrin $\alpha_{\mathrm{v}} \beta_{3}$ expression on tumor cells and neovasculature; MDA-MB-435: moderate integrin $\alpha_{v} \beta_{3}$ expression on tumor cells and neovasculature; PC-3: low integrin $\alpha_{\mathrm{v}} \beta_{3}$ expression on tumor cells and neovasculature). Tumor uptake values were calculated from quantification of SPECT/CT images. The \%ID/cm ${ }^{3}$ tumor uptake and $T / M$ ratios of 99mTc-3P-RGD 2 in the U87MG and PC-3 models were obtained from our previous report [64]. The changes in $\% \mathrm{ID} / \mathrm{cm}^{3}$ tumor uptake and $\mathrm{T} / \mathrm{M}$ ratios were calculated by subtracting the value on a specific date $(+I,+4$ and $+I I)$ from the value on day -1 . $*: p<0.05$, significantly different from those in the U87MG and PC-3 models. \#: $p<0.01$, significantly different from those in the U87MG and MDA-MB-435 models.

Effects of Linifanib on Tumor Vasculature and Integrin $\alpha_{\mathrm{v}} \beta_{3}$ Expression. Immunohistochemical staining was performed to study the impact of linifanib treatment on integrin $\alpha_{v} \beta_{3}$ and CD31 expression in MDA-MB-435 tumors. Figure 7 (top) shows overlay images of the tumor slices stained with hamster anti-integrin $\beta_{3}$ (red color) or rat anti-CD31 (green color) antibody in both vehicle and linifanib-treated groups. The yellow color in overlay images indicates the presence of integrin $\beta_{3}$ on new blood vessels. It was quite clear that the effect of linifanib therapy was on both tumor cells and tumor neovasculature as indicated by the disappearance of red (breast tumor cells) and yellow/orange (neovasculature) colors for integrin $\alpha_{v} \beta_{3}$ in the overlay images. After $24 \mathrm{~h}$ of linifanib therapy, the integrin $\alpha_{v} \beta_{3}$ on neovasculature disappeared almost completely while the tumor cell integrin $\alpha_{v} \beta_{3}$ expression level decreased steadily during the 11-day period (Figure 7: top). This was further supported by the pathological H\&E staining data of tumor slices in vehicle and linifanib-treated groups (Figure 7: bottom) at -1 and 1 days. Within 24 $\mathrm{h}$ after initiation of linifanib therapy, the blood vessel density was dramatically reduced. These data clearly 
show that linifanib treatment had a strong impact on both breast tumor cells and neovasculature.

Relationship between Tumor Response and Integrin $\boldsymbol{\alpha}_{\mathrm{v}} \boldsymbol{\beta}_{3} / \mathrm{CD} 31$ expression. Figure 8 shows plots of the $\% \mathrm{ID} / \mathrm{cm}^{3}$ tumor uptake changes after linifanib treatment against integrin $\alpha_{v} \beta_{3}$ (left) and CD31 (right) expression levels in the U87MG, MDA-MB-435 and PC-3 models at the time of diagnosis. The tumor uptake change was calculated by deducting the

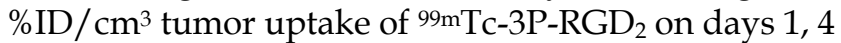
and 11 from its $\% \mathrm{ID} / \mathrm{cm}^{3}$ tumor uptake on -1 day for the same animal. Integrin $\alpha_{v} \beta_{3}$ and CD31 expression levels were obstained from the tumors $(0.1-0.3 \mathrm{~g})$ without significant necrosis. Obviously, there was an excellent linear relationship between $\% \mathrm{ID} / \mathrm{cm}^{3}$ tumor uptake changes (the tumor response or therapeutic effect) and the total integrin $\alpha_{\mathrm{v}} \beta_{3}$ expression levels (integrin $\alpha_{\mathrm{v}} \beta_{3}$ density) at the time of diagnosis (-1 day). The same linear relationship was also seen between the tumor response and the CD31 expression levels (blood vessel density).

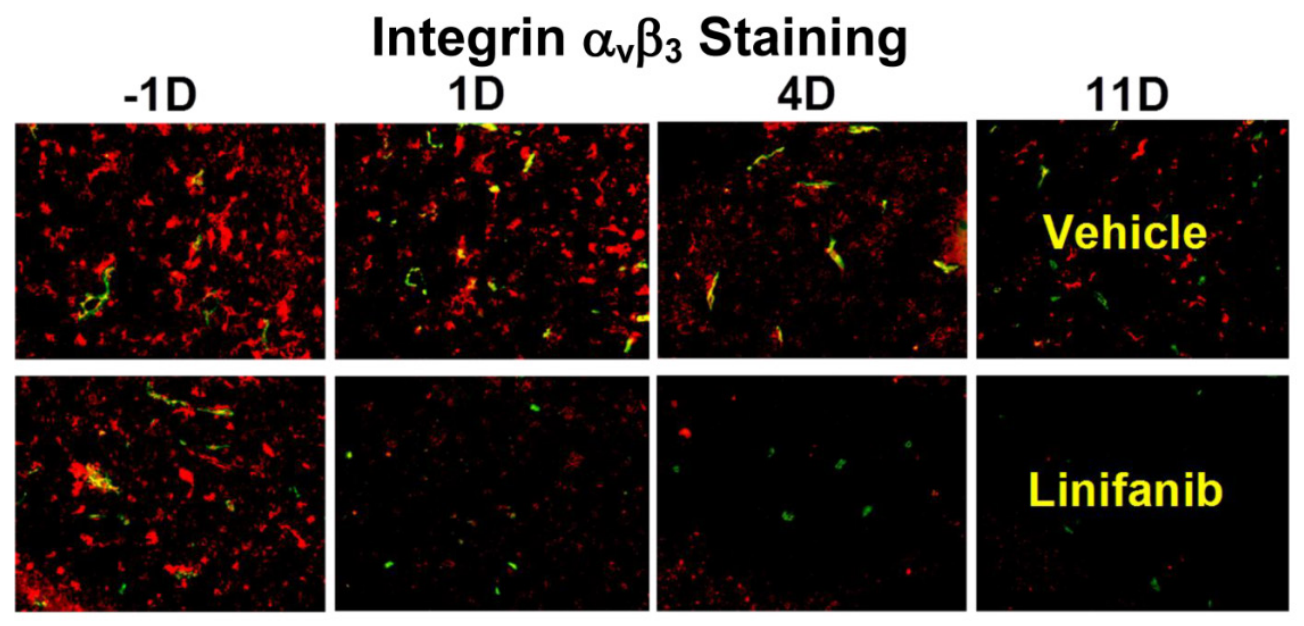

\section{H\&E Staining}

$-1 D$
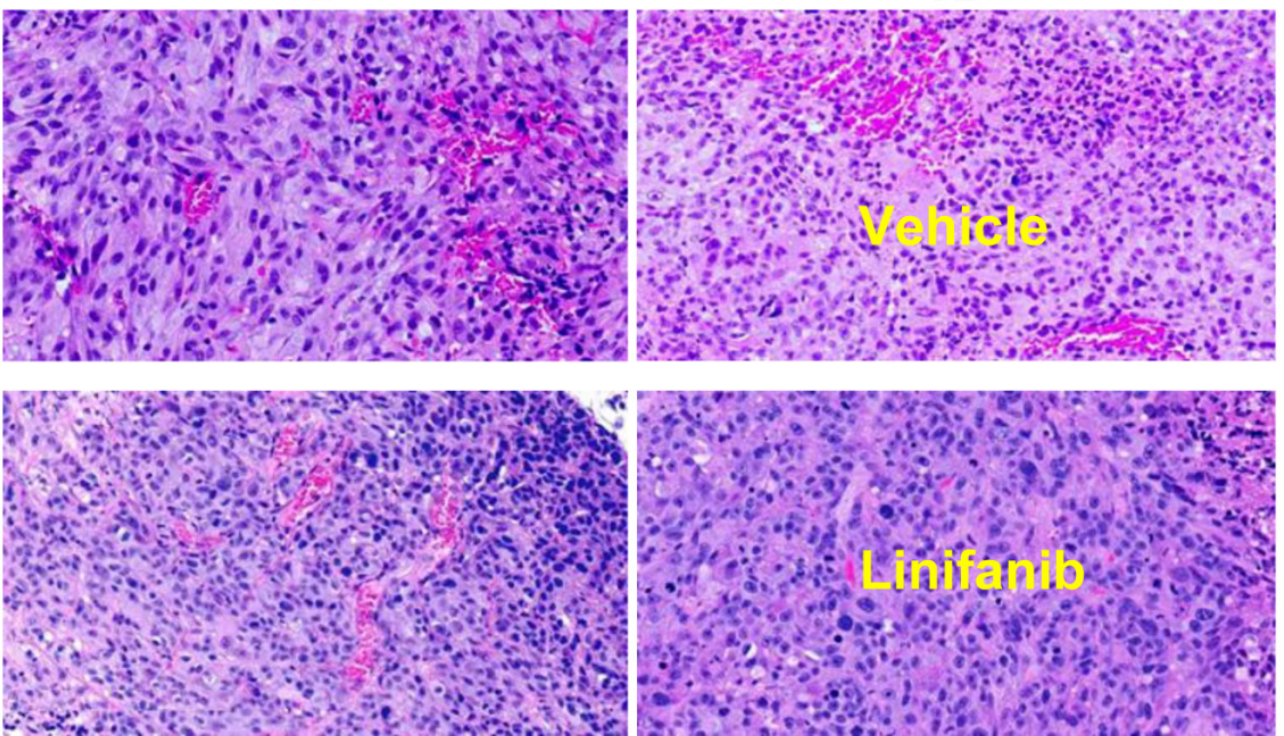

Fig 7. A: Overlay images of MDA-MB-435 tumor tisues after immunohistochemical staining for integrin $\beta_{3}$ and CD3I in vehicle (upper panel) and linifanib-treated groups (lower panel) to illustrate the changes in integrin $\beta_{3}$ expression level and blood vessel density during linifanib therapy. Tumor tissues were harvested at - I, I, 4 and II days after initiation of linifanib therapy. CD3 I was the marker for tumor blood vessels (both mature and newly formed), which was visualized with FITC (green color). Integrin $\beta_{3}$ was visualized with Cy3 (red color). The yellow color in overlay images indicates the presence of integrin $\beta_{3}$ on new blood vessels. B: Images of selected histological slice (H\&E stained) of tumor tissues from animals in the vehicle (upper panels) and linifanib-treated (lower panels) groups to illustrate vascular density changes after only one day of linifanib therapy. Red color indicates the presence of blood vessels. 

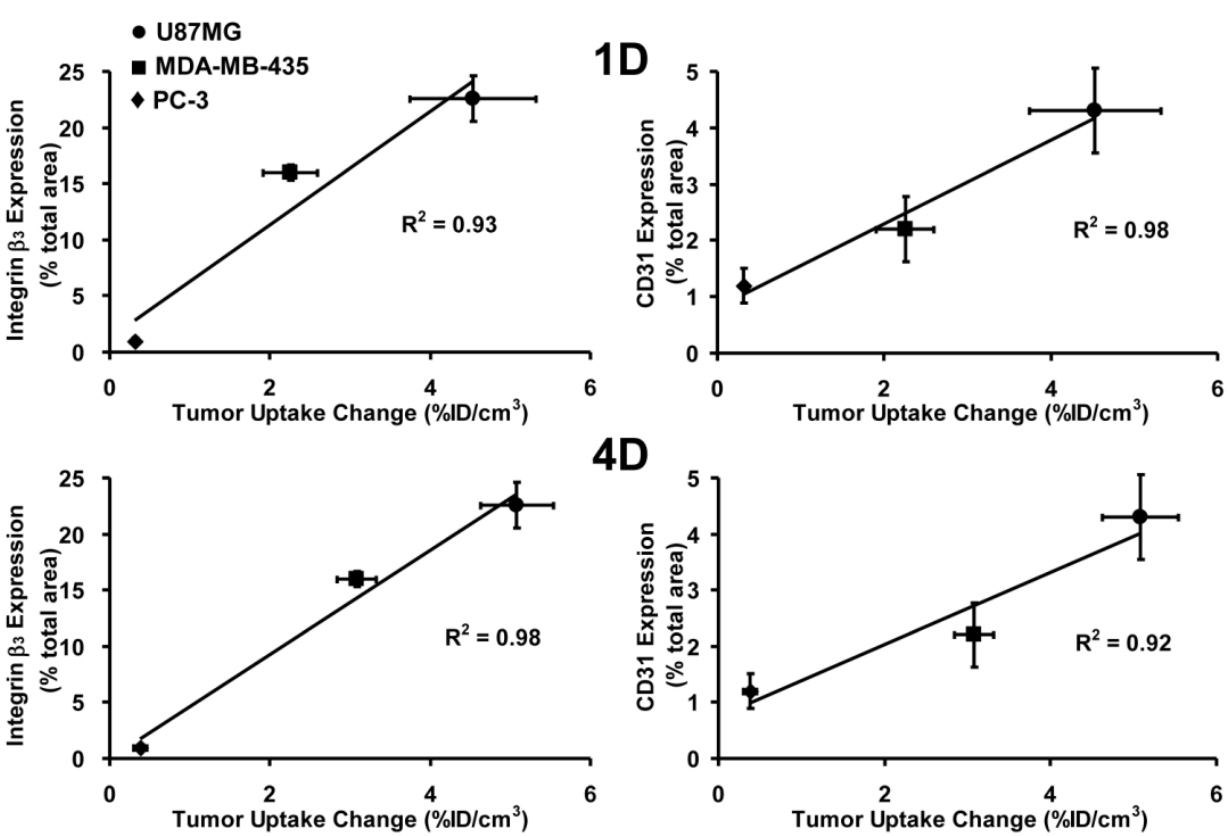

4D
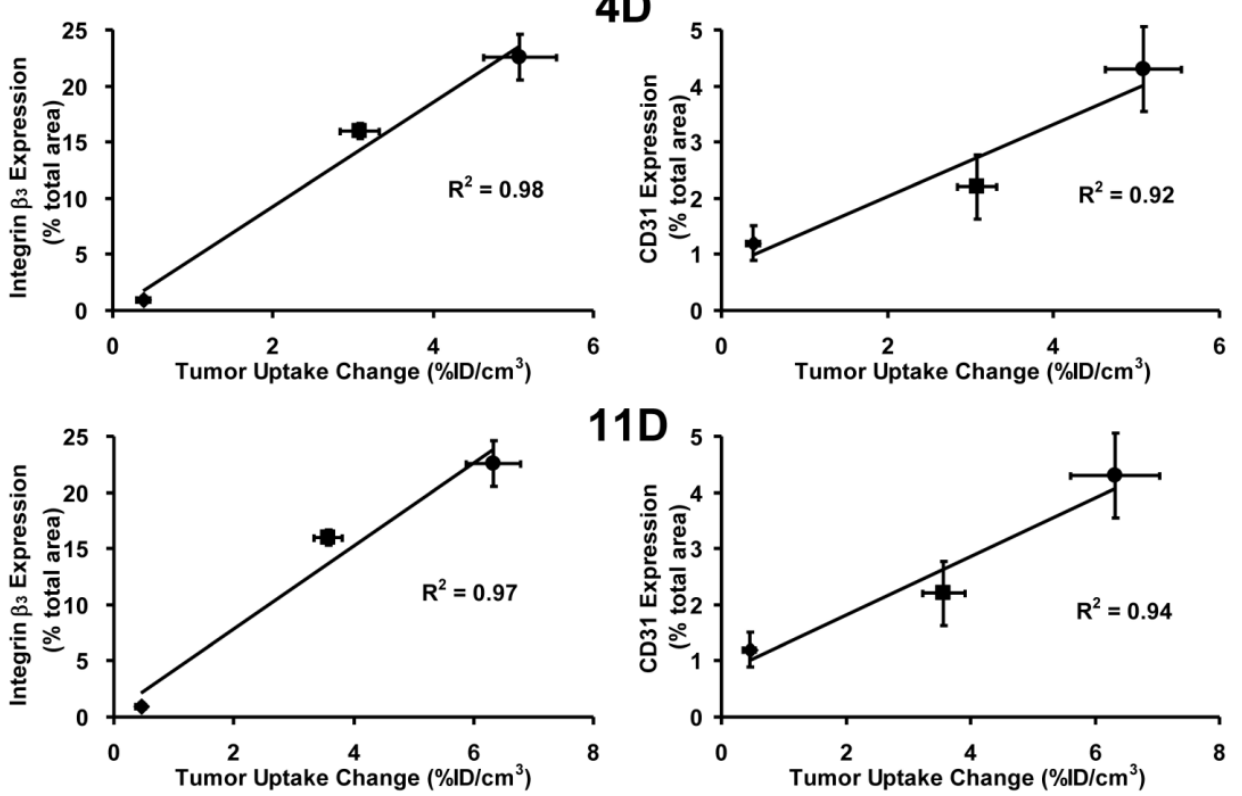

Fig 8. Linear relationship between the \%ID/cm ${ }^{3}$ tumor uptake change at days I (top), 4 (middle) and II (bottom) after linifanib therapy and the expression levels of integrin $\alpha_{v} \beta_{3}$ (left) and CD3I (right) in three animal models. The \%ID/cm ${ }^{3}$ tumor uptake values of $99 \mathrm{mTc}-3 \mathrm{P}-\mathrm{RGD} 2$ were calculated from SPECT/CT quantification, and reported as the mean plus/minus standard error of the mean based on results from five animals $(n=5)$. The $\% I D / \mathrm{cm}^{3}$ tumor uptake values and integrin $\alpha_{v} \beta_{3} / C_{3} 3 \mid$ expression levels in the U87MG and PC-3 tumors were obtained from our previous report [64]. The \%ID/cm 3 tumor uptake change was calculated by deducting the

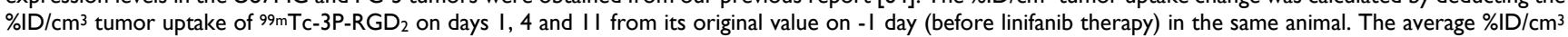
tumor uptake change is used as an indicator of tumor response to linifanib antiangiogenesis treatment.

Effects of $\mathrm{RGD}_{2}$ Therapy on Tumor Volume. Figure 9A shows the tumor growth curves during 42 days of study period for both vehicle $(n=5)$ and $\mathrm{RGD}_{2}$-treated $(\mathrm{n}=5)$ groups. No significant difference in tumor volumes was found over first 3 days after initiation of $\mathrm{RGD}_{2}$ therapy. After two doses of $\mathrm{RGD}_{2}(4$ days after initiation of $\mathrm{RGD}_{2}$ therapy), there was significant tumor volume reduction in $\mathrm{RGD}_{2}$-treated group. By the time of the final dose (10 days after initiation of $\mathrm{RGD}_{2}$ therapy), the tumor volume in the vehicle-treated group was almost $3 x$ larger than that in $\mathrm{RGD}_{2}$-treated group. Obviously, there was a significant therapeutic effect from $\mathrm{RGD}_{2}$ treatment on the basis of tumor volume change. However, $\mathrm{RGD}_{2}$ treatment had to be stopped after five doses of $\mathrm{RGD}_{2}$ because of toxicity, as indicated by significant weight loss (Figure 9B).
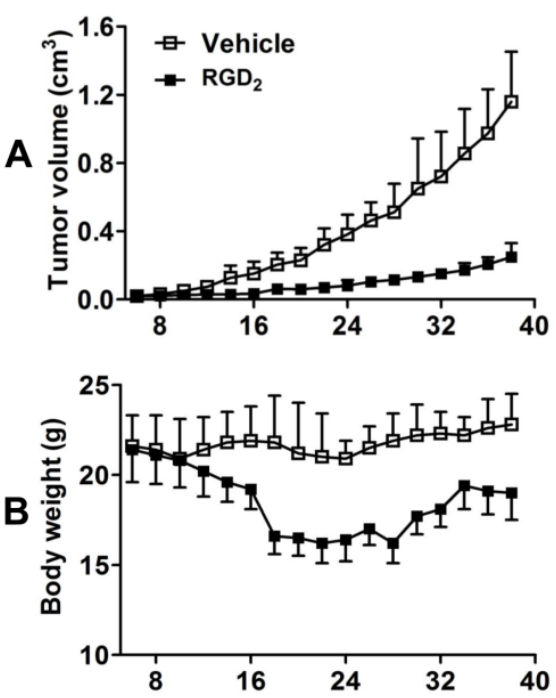

Fig 9. Tumor growth curves $(\mathbf{A})$ and body weight changes $(\mathbf{B})$ for vehicle $(\mathrm{n}=$ 5 ) and $R D_{2}$-treated $(n=5)$ groups in the xenografted MDA-MB-435 breast tumor model. Tumor size was calculated on the basis of caliper measurements

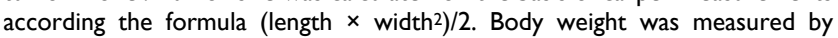
balance. $R G D_{2}$ treatment had to be stopped after five doses of $R G D_{2}$ because of toxicity, as indicated by significant weight loss. The body weight recovered after termination of $R_{G D_{2}}$ treatment. 
Effects of $\mathrm{RGD}_{2}$ Therapy on Tumor Uptake. SPECT/CT images (Figure 10: top) were obtained before $\mathrm{RGD}_{2}$ treatment, and at 21 and 35 days after inoculation of MDA-MB-435 cells. Tumor volumes (A), tumor uptake (B: \% ID and C: $\% \mathrm{ID} / \mathrm{cm}^{3}$ ) and T/M ratios (D) were calculated from SPECT/CT quantification. Since the tumor retention time of $\mathrm{RGD}_{2}$ was $\sim 15 \mathrm{~h}$ [65], a 7-day interval between the final $\mathrm{RGD}_{2}$ dosing and the first SPECT/CT imaging study was used to make sure that there was no significant blockage of ${ }^{99 m}$ Tc-3P-RGD 2 binding to integrin $\alpha_{v} \beta_{3}$. As expected, there was significant reduction in tumor volume (Figure 10A) and \% ID tumor uptake (Figure 10B) of $99 \mathrm{mTc}-3 \mathrm{P}-\mathrm{RGD}_{2}$ between the vehicle and
$\mathrm{RGD}_{2}$-treated animals. However, its $\% \mathrm{ID} / \mathrm{cm}^{3}$ tumor uptake was comparable in vehicle and $\mathrm{RGD}_{2}$-treated groups within experimental errors (Figure 10C: $p>$ 0.05 ) at 7 days post $R_{G D}$ treatment. By 21 days after $\mathrm{RGD}_{2}$ therapy, the $\% \mathrm{ID} / \mathrm{cm}^{3}$ uptake in $\mathrm{RGD}_{2}$-treated group was significantly higher than that in vehicle group (Figure 10C: $\mathrm{p}<0.05$ ) while $\mathrm{T} / \mathrm{M}$ ratios were almost identical at both time points (Figure 10D). $\mathrm{RGD}_{2}$ therapy resulted in significant reduction in both the tumor volume and \%ID tumor uptake (the tumor radioactivity) of ${ }^{99 m T c}-3 \mathrm{P}-\mathrm{RGD}_{2}$ (Figure 10: $\mathrm{A}$ and $\mathrm{B}$ ); but it also led to the enhanced $\% \mathrm{ID} / \mathrm{cm}^{3}$ tumor uptake (the radioactivity density) of $99 \mathrm{mTc}-3 \mathrm{P}-\mathrm{RGD}_{2}$ (Figure 10C).

\section{SPECT/CT Images}

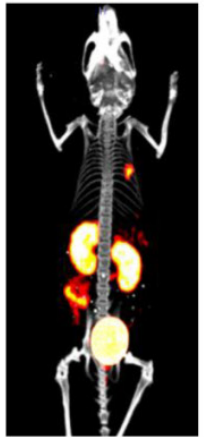

Before treatment

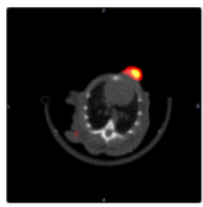

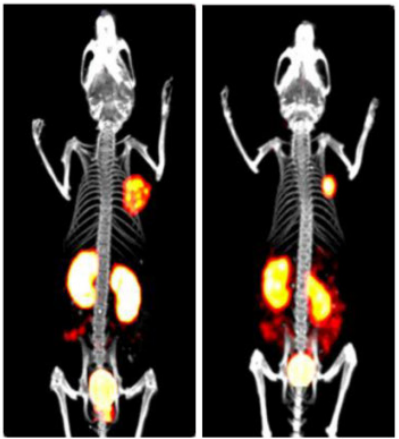

7 days after treatment

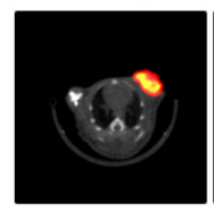

Vehicle

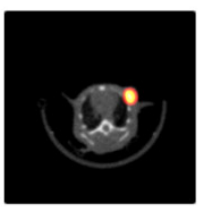

$\mathrm{RGD}_{2}$

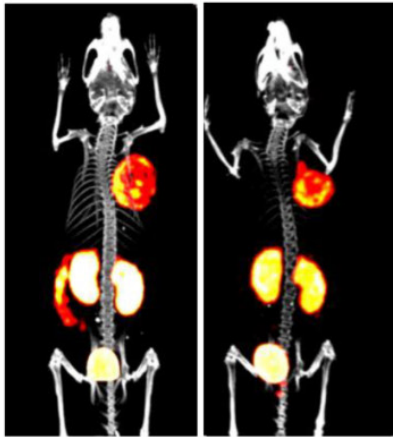

21 days after treatment

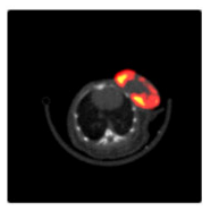

Vehicle

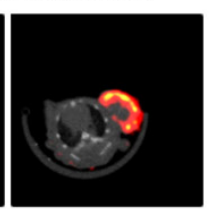

$\mathrm{RGD}_{2}$

\section{SPECT/CT Quantification Data}
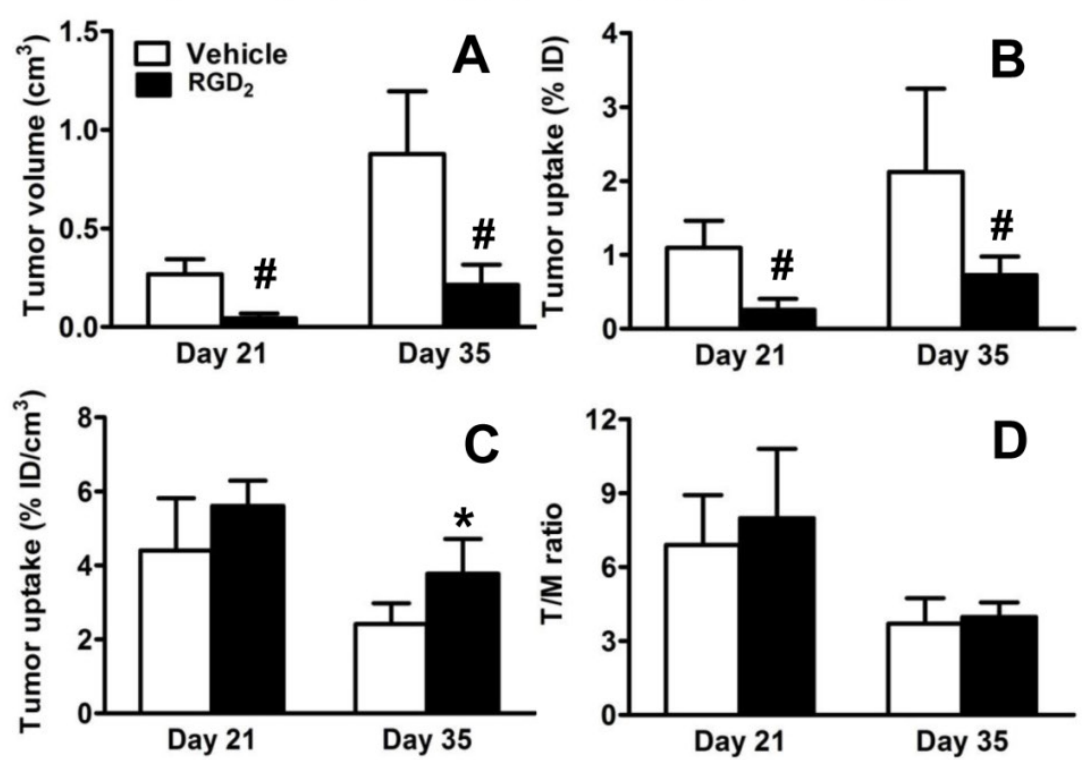

Fig 10. Top: The 3D and transverse views of SPECT/CT images of tumor-bearing mice before RGD 2 treatment, as well as on day 21 and 35 after inoculation of MDA-MB-435 cells (or on day 7 and 21 after final dose of RGD ). SPECT image at day 7 was used only for comparison purposes. Bottom: SPECT/CT quantification data, including tumor volumes (A), \%ID tumor uptake $(B), \% I D / \mathrm{cm}^{3}$ tumor uptake $(C)$, and T/M ratios $(D)$ in vehicle $(n=5)$ and $R G D_{2}$-treated $(n=5)$ groups. ${ }^{*} p<$ 0.05 and $\# p<0.01$ : significantly different from the vehicle-treated group. 


\section{Discussion}

In this study, we found that ${ }^{99 m} \mathrm{Tc}-3 \mathrm{P}-\mathrm{RGD}_{2}$ is an excellent radiotracer for imaging MDA-MB-435 tumors (Figure 1A). As shown in Figure 2, the uptake values (\% ID and $\% \mathrm{ID} / \mathrm{cm}^{3}$ ) of $99 \mathrm{mTc}-3 \mathrm{P}-\mathrm{RGD}_{2}$ from SPECT/CT is almost identical to those from biodistribution. There was also a linear relationship between

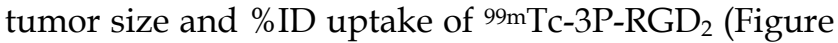
2: $\mathrm{A}$ and $\mathrm{C}$ ). These results strongly suggested that the tumor uptake obtained from SPECT/CT images can accurately reflect the total tumor integrin $\alpha_{\mathrm{v}} \beta_{3}$ expression. ${ }^{99 \mathrm{~m} T c}-3 \mathrm{P}-\mathrm{RGD}_{2}$ is useful for monitoring integrin $\alpha_{\mathrm{v}} \beta_{3}$ expression changes during tumor growth (Figure 1A).

$\left[{ }^{18} \mathrm{~F}\right] \mathrm{AH} 111585$ has been used to monitor sunitinib therapy response [43-45], and its tumor uptake was significantly reduced 2 days after sunitinib therapy. It was believed that $\left[{ }^{18} \mathrm{~F}\right] \mathrm{AH} 111585$ was better than [ $\left.{ }^{18} \mathrm{~F}\right] \mathrm{FDG}$ for imaging angiogenesis [45]. ${ }^{64} \mathrm{Cu}$-DOTA-RGD was used to monitor dasatinib therapy [46]. It was also found that dasatinib was able to significantly reduce the uptake of ${ }^{64} \mathrm{Cu}$-DOTA-RGD in the "treated" tumors. A significant challenge for $\left[{ }^{18} \mathrm{~F}\right] \mathrm{AH} 111585$ and many ${ }^{18} \mathrm{~F}$-based PET radiotracers to assume a wide-spread clinical utility is their poor clinical availability. In contrast, ${ }^{99 m T c}-3 P-R^{2} D_{2}$ is readily prepared with very high specific activity using a kit formulation [54,55]. From availability point of

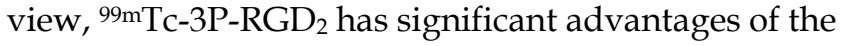
corresponding ${ }^{18} \mathrm{~F}$ PET radiotracers.

Inhibition of VEGF and PDGF receptors with linifanib normalizes tumor vasculature [9-11, 13, 14]. Since growth factors (e.g. VEGF) increase integrin $a_{v} \beta_{3}$ expression [40-42], inhibition of VEGF and PDGF receptors could lead to a decrease of integrin $\alpha_{v} \beta_{3}$ expression. This makes integrin $\alpha_{v} \beta_{3}$ a mechanistically relevant biomarker to assess the tumor response to linfanib therapy. In this study, we found significant decreases in the tumor uptake (\% ID and $\% \mathrm{ID} / \mathrm{cm}^{3}$ ) of ${ }_{99} \mathrm{~m}$ Tc-3P-RGD 2 prior to tumor volume changes after linifanib treatment (Figures 4). Changes in tumor vasculature were confirmed by IHC staining data (Figure 7A) and pathological H\&E analysis (Figure 7B).

It is interesting to note that the therapeutic effect of linifanib is not limited to tumor blood vessels. It is well-established that linifanib is a multi-targeted receptor tyrosine kinase inhibitor [9-14]. Since VEGF and PDGF receptors are overexpressed on tumor cells and neovasculature $[41,42]$, it is not surprising that linifanib has inhibitory effects on both tumor cells and tumor vasculature. There are two phases for the tumor response to linifanib therapy (Figure 5): a dramatic decrease in the tumor uptake (\% ID and \%ID/g) of ${ }^{99 m}$ Tc-3P-RGD 2 within the first $24 \mathrm{~h}$ after initiation of linifanib therapy, and a steady tumor uptake reduction over the next 10 days of study period. The IHC and H\&E staining data (Figure 7) suggest that the rapid decrease in tumor uptake of ${ }^{99 m} \mathrm{Tc}-3 \mathrm{P}-\mathrm{RGD}_{2}$ is most likely induced by antiangiogenic effect of linifanib on tumor neovasculature while the slow tumor uptake reduction is caused by either its direct inhibitory effect on tumor cells or slow tumor cell apoptosis as a result of normalization of tumor vasculature $[9-11,13,14]$. This explanation is supported by the sharp decrease of CD31 signals (Figure 7A) and tumor microvessel density (Figure 7B) over the first $24 \mathrm{~h}$ after initiation of linifanib treatment, followed by slow disappearance of fluorescence intensity from integrin $\beta_{3}$ on tumor cells over the next 10 days of study period (Figure 7A).

In our previous study [64], we found that there was a significant decrease in tumor uptake (\%ID and

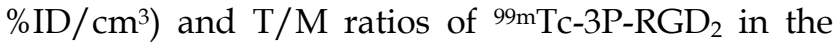
xenografted U87MG model while no significant changes in tumor volume or tumor uptake of ${ }^{99 m}$ Tc-3P-RGD 2 were seen in the xenografted PC-3 model after linifanib treatment. In this study, we found that the changes in tumor volume (Figure 4)

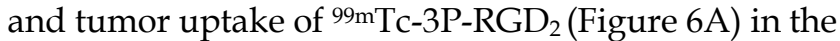
MDA-MB-435 model were between those observed in the U87MG and PC-3 models. This is consistent with the relative integrin $\alpha_{v} \beta_{3}$ expression levels on three xenografted tumors $[56,66]$, and reciprocal relationship between integrin $\alpha_{v} \beta_{3}$ and VEGFR2 [40-42]. We also found that there is a linear relationsip between the integrin $\alpha_{v} \beta_{3} / C D 31$ expression levels and the tumor response, as indicated by changes in $\% \mathrm{ID} / \mathrm{cm}^{3}$ tumor uptake and $\mathrm{T} / \mathrm{M}$ ratios of $99 \mathrm{mTc}-3 \mathrm{P}-\mathrm{RGD}_{2}$ (Figure 8). Highly vascularized tumors (e.g. U87MG) with higher expression level of integrin $\alpha_{v} \beta_{3}$ and CD31 have better tumor response to linifanib therapy than poorly vascularized tumors (e.g. PC-3) with low expression levels of integrin $\alpha_{v} \beta_{3}$ and CD31. 99mTc-3P-RGD 2 has the potential as a pre-treatment screening tool to select appropriate patients who will benefits most from the antiangiogenic linifanib treatment. If the tumor in cancer patient has a high expression level of integrin $\alpha_{v} \beta_{3}$, as indicated by the

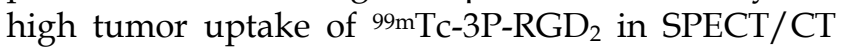
images at the time of diagnosis, antiangiogenic linifanib therapy would more likely be effective. If the tumor has very little integrin $a_{v} \beta_{3}$ expression (low

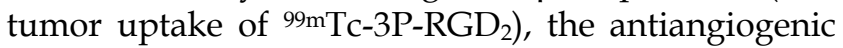
therapy would not be effective regardless the amount of linifanib administered into each cancer patient.

It is important to note that there are no accurate techniques to quantify absolute integrin $\alpha_{v} \beta_{3}$ expression levels. Western blotting was used to determine 
the total integrin $\alpha_{v} \beta_{3}$ protein concentration in tumor tissues $[44,45,56,67,68]$; but the percentage of integrin $\alpha_{v} \beta_{3}$ recovery from the tumor tissue and its activation state remained unknown. We have been using IHC staining with anti-integrin $\beta_{3}$ antibodies to determine the relative expression levels of integrin $\alpha_{v} \beta_{3}$ in the tumor tissues $[56,66]$. This technique is a better fit to reflect the activation state of integrin $\alpha_{v} \beta_{3}$ in acetone-fixed tumor tissues since only the activated integrin $\alpha_{v} \beta_{3}$ is able to bind the fluorescence-labeled anti-integrin $\beta_{3}$ monoclonal antibody. We also found that the primary antibody is very important for IHC staining of tumor tissues. In this study, we use hamster anti-human integrin $\beta_{3}$ antibody for staining of integrin $\alpha_{v} \beta_{3}$ on both tumor cells and neovasculature mainly because of the murine nature of xenografted tumor tissues. It must be noted that quantification of absolute fluorescent intensity is operator-dependent and subjected to individual interpretation. Tumors of different sizes might have different integrin $\alpha_{v} \beta_{3}$ expression patterns because of tumor necrosis. The integrin $a_{v} \beta_{3}$ expression pattern is heterogeneous even in the same tumor tissue. Thus, the relative expression levels of integrin $\alpha_{v} \beta_{3}$ and CD31 only represent the status under specific experimental conditions, such as the primary integrin $\alpha_{v} \beta_{3}$ monoclonal antibody, animal species, inoculation location of tumor cells, tumor types, and tumor size.

As illustrated in this study, there is significant challenge in using ${ }^{99 m T c}-3 P-R_{2} D_{2}$ to monitor early tumor response to $\mathrm{RGD}_{2}$ therapy. Since ${ }^{99 m T c}-3 P-R_{G D}$ and $R_{2} D_{2}$ target the same receptor, there must be a waiting period to allow $\mathrm{RGD}_{2}$ to dissociate completely from integrin $\alpha_{\mathrm{v}} \beta_{3}$ sites before us-

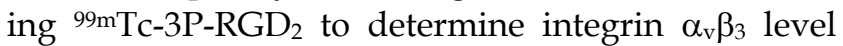
changes after $\mathrm{RGD}_{2}$ therapy. Otherwise, it would be difficult to determine if changes in tumor uptake are actually caused by its blocking effect or therapeutic effect. It is also important to note that the waiting period also depends on tumor retention time of the anti- $\alpha_{v} \beta_{3}$ agent. If its tumor retention time is short $(2-3$ $\mathrm{h})$, it is possible to image tumors with ${ }^{99 \mathrm{mTc}-3 \mathrm{P}-\mathrm{RGD}_{2}}$ $24 \mathrm{~h}$ ( $\sim 10$ half-lives) after anti- $\mathrm{a}_{\mathrm{v}} \beta_{3}$ therapy. Since its tumor retention time is $\sim 15 \mathrm{~h}$ [65], it would take $6-7$ days for $\mathrm{RGD}_{2}$ to dissociate completely from integrin $\alpha_{\mathrm{v}} \beta_{3}$ sites. During this period, the tumor might undergo significant biological changes. Therefore, it is difficult to use the integrin $\alpha_{v} \beta_{3}$-targeted radiotracers (e.g. ${ }^{99 m} \mathrm{Tc}-3 \mathrm{P}-\mathrm{RGD}_{2}$ ) to accurately monitor early tumor response to anti- $\alpha_{v} \beta_{3}$ therapy.

There is no doubt that $\mathrm{RGD}_{2}$ can significantly reduce the tumor size (Figure 10A) and \% ID tumor uptake (Figure 10B) of $99 \mathrm{mTc}-3 \mathrm{P}-\mathrm{RGD}_{2}$; but its $\% \mathrm{ID} / \mathrm{cm}^{3}$ tumor uptake in $\mathrm{RGD}_{2}$-treated group was higher $(p<0.05)$ than that in vehicle-treated group
(Figure 10C). It is possible that $\mathrm{RGD}_{2}$ was able to block the integrin $\alpha_{v} \beta_{3}$ sites in $R_{G D}$-treated group, resulting in tumor growth inhibition, as indicated by tumor volume reduction. Once $\mathrm{RGD}_{2}$ therapy stopped, $\mathrm{RGD}_{2}$ slowly dissociated from tumor cells and neovasculature. As a result, integrin $\alpha_{v} \beta_{3}$ is activated again. Recently it was reported that low concentrations of integrin $\alpha_{v} \beta_{3}$ and $\alpha_{v} \beta_{5}$ inhibitors (e.g. Cilengitide) can stimulate tumor growth and angiogenesis by altering $\alpha_{v} \beta_{3}$ integrin and VEGFR-2 trafficking, thereby promoting endothelial cell migration to VEGF [69]. That might explain why the \%ID/g tumor uptake of ${ }^{99 m} \mathrm{Tc}-3 \mathrm{P}-\mathrm{RGD}_{2}$ in $\mathrm{RGD}_{2}$-treated group was higher than that in vehicle-treated group 3 weeks after $\mathrm{RGD}_{2}$ therapy (Figure 10C). More studies are needed to understand the integrin $\alpha_{v} \beta_{3}$ expression or activation state changes after anti- $\alpha_{v} \beta_{3} R_{G D}$ therapy, as well as their relationship with the $\% \mathrm{ID} / \mathrm{g}$ tumor uptake of 99mTc-3P-RGD 2

\section{CONCLUSION}

In this study, we clearly show that 99mTc-3P-RGD 2 SPECT/CT is a useful molecular imaging tool for monitoring the integrin $\alpha_{\mathrm{v}} \beta_{3}$ expression changes during breast tumor growth or during/after linifanib antiangiogenic therapy. ${ }^{99 \mathrm{mTc}-3 \mathrm{P}-\mathrm{RGD}_{2}}$ SPECT/CT is also a useful pre-treatment screening tool to identify the cancer patient who will benefits best from antiangiogenic therapy with linifanib or related antiangiogenic drugs of the same or similar mechanism. However, it is difficult to use the integrin

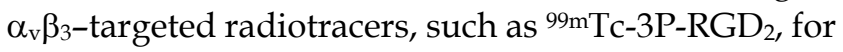
monitoring the early tumor response to anti- $\alpha_{\mathrm{v}} \beta_{3}$ therapy with Cilengitide or $\mathrm{RGD}_{2}$. This conclusion may also apply to other radiotracers and anti-cancer drugs that target the same receptor.

\section{ACKNOWLEDGEMENTS}

Authors thank AbbVie Inc. (North Chicago, IL) for the use of Linifanib. This work was supported by Purdue University, the Challenge Research Award from Purdue Cancer Center, the Indiana Clinical and Translational Sciences Institute funded in part by grant Number TR000006 (Clinical and Translational Award) from the National Institutes of Health, National Center for advancing Translational Science, and R01 CA115883 (S.L.) from the National Cancer Institute.

\section{COMPETING INTERESTS}

The authors have declared that no competing interest exists. 


\section{REFERENCES}

1. Folkman J. Role of angiogenesis in tumor growth and metastasis. Semin Oncol 2002;29:15-18.

2. Mousa SA. Anti-integrin as novel drug-discovery targets: potential therapeutic and diagnostic implications. Curr Opin Chem Biol 2002;6:534-541.

3. Guo W, Giancotti FG. Integrin signalling during tumour progression. Nat Rev Mol Cell Biol 2004;5:816-826.

4. Felding-Habermann B. Integrin adhesion receptors in tumor metastasis. Clin Exp Metastasis 2003;20:203-213.

5. Bergers G, Benjamin LE. Tumorigenesis and the angiogenic switch. Nat Rev Cancer 2003;3:401-410.

6. Bergers G, Song S, Meyer-Morse N, Bergsland E, Hanahan D. Benefits of targeting both pericytes and endothelial cells in the tumor vasculature with kinase inhibitors. J Clin Invest 2003;111:1287-1295.

7. Ferrara N, Kerbel RS. Angiogenesis as a therapeutic target. Nature 2005;438:967-974.

8. Haddley K. Linifanib Receptor tyrosine kinase inhibitor Oncolytic. Drug Future 2010;35:106-112

9. Zhou J, Goh BC, Albert DH, Chen CS. ABT-869, a promising multi-targeted tyrosine kinase inhibitor: from bench to bedside. J Hematol Oncol 2009;2:33-45.

10. Jiang F, Albert DH, Luo Y, Tapang P, Zhang K, Davidsen SK, Fox GB, Lesniewski R, McKeegan EM. ABT-869, a multitargeted receptor tyrosine kinase inhibitor, reduces tumor microvascularity and improves vascular wall integrity in preclinical tumor models. J Pharmacol Exp Ther 2011;338:134-142.

11. Shankar DB, Li J, Tapang P, Owen McCall J, Pease LJ, Dai Y, Wei RQ, Albert DH, Bouska JJ, Osterling DJ, Guo J, Marcotte PA, Johnson EF, Soni N, Hartandi K, Michaelides MR, Davidsen SK, Priceman SJ, Chang JC, Rhodes K, Shah N, Moore TB, Sakamoto KM, Glaser KB. ABT-869, a multitargeted receptor tyrosine kinase inhibitor: inhibition of FLT3 phosphorylation and signaling in acute myeloid leukemia. Blood 2007;109:3400-3408.

12. Hernandez-Davies JE, Zape JP, Landaw EM, Tan X, Presnell A, Griffith D, Heinrich MC, Glaser KB, Sakamoto KM. The multitargeted receptor tyrosine kinase inhibitor linifanib (ABT-869) induces apoptosis through an Akt and glycogen synthase kinase $3 \beta$-dependent pathway. Mol Cancer Ther 2011;10:949-959.

13. Zhang Y, Cole T, Tapang P, Luo F, Hradil V, Jiang F, Luo Y, Albert D, Fox GB. Total lesion glycolysis and FDG SUV as early readouts of tumor response to Linifanib (ABT-869) in SCID mice with HT1080 xenografts. J Nucl Med 2010;51:111

14. Luo Y, Jiang F, Cole TB, Hradil VP, Reuter D, Chakravartty A, Albert DH, Davidsen SK, Cox BF, McKeegan EM, Fox GB. A novel multi-targeted tyrosine kinase inhibitor, linifanib (ABT-869), produces functional and structural changes in tumor vasculature in an orthotopic rat glioma model. Cancer Chemother Pharmacol 2012;69:911-921.

15. Wong CI, Koh TS, Soo R, Hartono S, Thng CH, McKeegan E, Yong WP, Chen CS, Lee SC, Wong J, Lim R, Sukri N, Lim SE, Ong AB, Steinberg J, Gupta N, Pradhan R, Humerickhouse R, Goh BC. Phase I and biomarker study of ABT-869, a multiple receptor tyrosine kinase inhibitor, in patients with refractory solid malignancies. J Clin Oncol 2009;27:4718-4726.

16. Tannir NM, Wong YN, Kollmannsberger CK, Ernstoff MS, Perry DI, Appleman LJ, Posadas EM, Cho D, Choueiri TK, Coates A, Gupta N, Pradhan R, Qian J, Chen J, Scappaticci FA, Ricker JL, Carlson DM, Michaelson MD. Phase 2 trial of linifanib (ABT-869) in patients with advanced renal cell cancer after sunitinib failure. Eur J Cancer. 2011;47:2706-2714.

17. Foote RL, Weidner N, Harris J, Hammond E, Lewis JE, Vuong T, Ang KK, Fu KK. Evaluation of tumor angiogenesis measured with microvessel density (MVD) as a prognostic indicator in nasopharyngeal carcinoma: results of RTOG 9505. Int J Radiat Oncol Biol Phys 2005;61:745-753.

18. El-Assal ON, Yamanoi A, Soda Y, Yamaguchi M, Igarashi M, Yamamoto A, Nabika T, Nagasue N. Clinical significance of microvessel density and vascular endothelial growth factor expression in hepatocellular carcinoma and surrounding liver: possible involvement of vascular endothelial growth factor in the angiogenesis of cirrhotic liver. Hepatology 1998;27:1554-1562.

19. O'Connor JP, Jackson A, Parker GJ, Jayson GC. DCE-MRI biomarkers in the clinical evaluation of antiangiogenic and vascular disrupting agents. Br J Cancer 2007;96:189-195.

20. Checkley D, Tessier JJ, Kendrew J, Waterton IC, Wedge SR. Use of dynamic contrast-enhanced MRI to evaluate acute treatment with ZD6474, a VEGF signalling inhibitor, in PC-3 prostate tumours. Br J Cancer 2003;89:1889-1895.

21. Evelhoch JL, LoRusso PM, He Z, DelProposto Z, Polin L, Corbett TH, Langmuir P, Wheeler C, Stone A, Leadbetter J, Ryan AJ, Blakey DC, Waterton JC. Magnetic resonance imaging measurements of the response of murine and human tumors to the vascular-targeting agent ZD6126. Clin Cancer Res 2004; 10:3650-3657.

22. Bauerle T, Komljenovic D, Merz M, Berger MR, Goodman SL, Semmler W. Cilengitide inhibits progression of experimental breast cancer bone metastases as imaged noninvasively using VCT, MRI and DCE-MRI in a longitudinal in vivo study. Int J Cancer 2011;128:2453-2462.

23. Liapis $H$, Flath $A$, Kitazawa S. Integrin $\alpha_{v} \beta_{3}$ expression by bone-residing breast cancer metastases. Diagn Mol Pathol 1996;5:127-135.

24. Sengupta S, Chattopadhyay N, Mitra A, Ray S, Dasgupta S, Chatterjee A. Role of $\alpha_{\mathrm{v}} \beta_{3}$ integrin receptors in breast tumor. J Exp Clin Cancer Res 2001;20:585-590
25. Gasparini G, Brooks PC, Biganzoli E, Vermeulen PB, Bonoldi E, Dirix LY, Ranieri G, Miceli R, Cheresh DA. Vascular integrin $\alpha_{v} \beta_{3}$ : a new prognostic indicator in breast cancer. Clin Cancer Res 1998;4:2625-2634.

26. Cooper $\mathrm{CR}$, Chay $\mathrm{CH}$, Pienta KJ. The role of $\alpha_{v} \beta_{3}$ in prostate cancer progression. Neoplasia 2002;4:191-194.

27. Carreiras F, Denoux Y, Staedel C, Lehmann M, Sichel F, Gauduchon P. Expression and localization of $\mathrm{a}_{\mathrm{v}}$ integrins and their ligand vitronectin in normal ovarian epithelium and in ovarian carcinoma. Gynecol Oncol 1996;62:260-267.

28. Falcioni R, Cimino L, Gentileschi MP, D'Agnano I, Zupi G, Kennel SJ, Sacchi A. Expression of $\beta 1, \beta 3, \beta 4$, and $\beta 5$ integrins by human lung carcinoma cells of different histotypes. Exp Cell Res 1994;210:113-122.

29. Natali PG, Hamby CV, Felding-Habermann B, Liang B, Nicotra MR, Di Filippo F, Giannarelli D, Temponi M, Ferrone S. Clinical significance of $\alpha_{v} \beta_{3}$ integrin and intercellular adhesion molecule-1 expression in cutaneous malignant melanoma lesions. Cancer Res 1997;57:1554-1560.

30. Gingras MC, Roussel E, Bruner JM, Branch CD, Moser RP. Comparison of cell adhesion molecule expression between glioblastoma multiforme and autologous normal brain tissue. J Neuroimmunol 1995;57:143-153

31. Bello L, Francolini M, Marthyn P, Zhang J, Carroll RS, Nikas DC, Strasser JF, Villani R, Cheresh DA, Black PM. $\alpha_{v} \beta_{3}$ and $\alpha_{v} \beta_{5}$ integrin expression in glioma periphery. Neurosurgery 2001:49:380-389.

32. Felding-Habermann B, O'Toole TE, Smith JW, Fransvea E, Ruggeri ZM, Ginsberg MH, Hughes PE, Pampori N, Shattil SJ, Saven A, Mueller BM. Integrin activation controls metastasis in human breast cancer. Proc Natl Acad Sci U S A 2001;98:1853-1858.

33. Shattil SJ. Signaling through platelet integrin $\alpha_{\mathrm{Il}} \beta_{3}$ : inside-out, outside-in, and sideways. Thromb Haemost 1999;82:318-325.

34. Pécheur I, Peyruchaud O, Serre CM, Guglielmi J, Voland C, Bourre F, Margue C, Cohen-Solal M, Buffet A, Kieffer N, Clézardin P. Integrin $\alpha_{v} \beta_{3}$ expression confers on tumor cells a greater propensity to metastasize to bone. FASEB J 2002;16:1266-1268

35. Duan X, Jia SF, Zhou Z, Langley RR, Bolontrade MF, Kleinerman ES. Association of $a_{v} \beta_{3}$ integrin expression with the metastatic potential and migratory and chemotactic ability of human osteosarcoma cells. Clin Exp Metastasis 2004;21:747-753.

36. Zitzmann S, Ehemann V, Schwab M. Arginine-glycine-aspartic acid (RGD)-peptide binds to both tumor and tumor-endothelial cells in vivo. Cancer Res 2002;62:5139-5143.

37. Meyer A, Auernheimer J, Modlinger A, Kessler H. Targeting RGD recognizing integrins: drug development, biomaterial research, tumor imaging and targeting. Curr Pharm Des 2006;12:2723-2747.

38. Liu S. Radiolabeled cyclic RGD peptides as integrin $\alpha_{v} \beta_{3}$-targeted radiotracers: maximizing binding affinity via bivalency. Bioconjug Chem 2009;20:2199-2213.

39. Zhou Y, Chakraborty S, Liu S. Radiolabeled Cyclic RGD Peptides as Radiotracers for Imaging Tumors and Thrombosis by SPECT. Theranostics 2011;1:58-82.

40. Mahabeleshwar GH, Feng W, Reddy K, Plow EF, Byzova TV. Mechanisms of integrin-vascular endothelial growth factor receptor cross-activation in angiogenesis. Circ Res 2007;101:570-580.

41. Soldi R, Mitola S, Strasly M, Defilippi P, Tarone G, Bussolino F. Role of $\alpha_{v} \beta_{3}$ integrin in the activation of vascular endothelial growth factor receptor-2. EMBO J 1999:18:882-892

42. Somanath PR, Ciocea A, Byzova TV. Integrin and growth factor receptor alliance in angiogenesis. Cell Biochem Biophys 2009;53:53-64.

43. Beer AJ, Schwaiger M. PET of $\alpha_{v} \beta_{3}$-integrin and $\alpha_{v} \beta_{3}$-integrin expression with ${ }^{18} \mathrm{~F}$-fluciclatide for assessment of response to targeted therapy: ready for prime time? J Nucl Med 2011;52:335-337.

44. Morrison MS, Ricketts SA, Barnett J, Cuthbertson A, Tessier J, Wedge SR. Use of a novel Arg-Gly-Asp radioligand, ${ }^{18} \mathrm{~F}-\mathrm{AH} 111585$, to determine changes in tumor vascularity after antitumor therapy. J Nucl Med 2009;50:116-122.

45. Battle MR, Goggi JL, Allen L, Barnett J, Morrison MS. Monitoring tumor response to antiangiogenic sunitinib therapy with $18 \mathrm{~F}$-fluciclatide, an ${ }^{18}$ F-labeled $\alpha_{v} \beta_{3}$-integrin and $\alpha_{v} \beta_{5}$-integrin imaging agent. J Nucl Med 2011;52:424-430.

46. Dumont RA, Hildebrandt I, Su H, Haubner R, Reischl G, Czernin JG, Mischel PS, Weber WA. Noninvasive imaging of $\alpha_{v} \beta_{3}$ function as a predictor of the antimigratory and antiproliferative effects of dasatinib. Cancer Res 2009;69:3173-3179.

47. Meyer A, Auernheimer J, Modlinger A, Kessler H. Targeting RGD recognizing integrins: drug development, biomaterial research, tumor imaging and targeting. Curr Pharm Des 2006;12:2723-2747.

48. Cai W, Chen X. Multimodality molecular imaging of tumor angiogenesis. J Nucl Med 2008;49 (Suppl 2):113-128.

49. Dijkgraaf I, Boerman OC. Molecular imaging of angiogenesis with SPECT. Eur J Nucl Med Mol Imaging 2010;37 (Suppl 1):104-113.

50. Niu G, Chen X. Has molecular and cellular imaging enhanced drug discovery and drug development? Drugs R D 2008;9:351-368.

51. Tateishi $U$, Oka $T$, Inoue $T$. Radiolabeled RGD Peptides as Integrin $\alpha_{\mathrm{v}} \beta_{3}$-targeted PET Tracers. Curr Med Chem 2012;19:3301-3309.

52. Haubner R, Wester HJ. Radiolabeled tracers for imaging of tumor angiogenesis and evaluation of anti-angiogenic therapies. Curr Pharm Des 2004;10:1439-1455.

53. Michalski MH, Chen X. Molecular imaging in cancer treatment. Eur J Nucl Med Mol Imaging 2011; 38: 358-377. 
54. Wang L, Shi J, Kim YS, Zhai S, Jia B, Zhao H, Liu Z, Wang F, Chen X, Liu S. Improving tumor-targeting capability and pharmacokinetics of $99 \mathrm{mTc}$-labeled cyclic RGD dimers with PEG $_{4}$ linkers. Mol Pharm 2009; 6:231-245.

55. Jia B, Liu Z, Zhu Z, Shi J, Jin X, Zhao H, Li F, Liu S, Wang F. Blood clearance kinetics, biodistribution and radiation dosimetry of a kit-formulated integrin $\alpha_{v} \beta_{3}$-selective radiotracer ${ }^{99 m T c}-3 P R G D_{2}$ in non-human primates. Mol Imaging Biol 2011;13:730-736.

56. Zhou Y, Kim YS, Chakraborty S, Shi J, Gao H, Liu S. 99mTc-labeled cyclic RGD peptides for noninvasive monitoring of tumor integrin $\alpha_{v} \beta_{3}$ expression. Mol Imaging 2011;10:386-397.

57. Shao G, Zhou Y, Wang F, Liu S. Monitoring glioma growth and tumor necrosis with the U-SPECT-II/CT scanner by targeting integrin $\alpha_{v} \beta_{3}$. Mol Imaging 2013;12:39-48.

58. Zhou Y, Shao G, Liu S. Monitoring breast tumor lung metastasis by U-SPECT-II/CT with an integrin $\alpha_{v} \beta_{3}$-targeted radiotracer $99 \mathrm{mTc}-3 \mathrm{P}-\mathrm{RGD}_{2}$. Theranostics 2012;2:577-588.

59. Suzuki M, Mose ES, Montel V, Tarin D. Dormant cancer cells retrieved from metastasis-free organs regain tumorigenic and metastatic potency. Am J Pathol 2006;169:673-681.

60. Sellappan S, Grijalva R, Zhou X, Yang W, Eli MB, Mills GB, Yu D. Lineage infidelity of MDA-MB-435 cells: expression of melanocyte proteins in a breast cancer cell line. Cancer Res 2004;64:3479-3485.

61. Ellison G, Klinowska T, Westwood RF, Docter E, French T, Fox JC. Further evidence to support the melanocytic origin of MDA-MB-435. Mol Pathol 2002;55:294-299.

62. Chambers AF. MDA-MB-435 and M14 cell lines: identical but not M14 melanoma? Cancer Res 2009; 69:5292-5293.

63. Jain RK. Transport of molecules in the tumor interstitium: a review. Cancer Res 1987;47:3039-3051.

64. Ji S, Zhou Y, Voorbach MJ, Shao G, Zhang Y, Fox GB, Albert DH, Luo Y, Liu S, Mudd S. Monitoring tumor response to linifanib therapy with SPECT/CT using the $\alpha_{v} \beta_{3}$-targeted radiotracer ${ }^{99 m T c}-3 P-R_{G D}$. J Pharmacol Exp Ther 2013;346:251-258.

65. Shi J, Zhou Y, Chakraborty S, Kim YS, Jia B, Wang F, Liu S. Evaluation of ${ }^{111}$ In-labeled cyclic RGD peptides: effects of peptide and $\mathrm{PEG}_{4}$ multiplicity on their tumor uptake, excretion kinetics and metabolic stability. Theranostics 2011;1:322-340.

66. Zhou Y, Kim YS, Lu X, Liu S. Evaluation of 99mTc-labeled cyclic RGD dimers: impact of cyclic RGD peptides and $99 \mathrm{mTc}$ chelates on biological properties. Bioconjug Chem 2012;23:586-595.

67. Wu Y, Zhang X, Xiong Z, Cheng Z, Fisher DR, Liu S, Gambhir SS, Chen X MicroPET imaging of glioma integrin $\alpha_{\mathrm{v}} \beta_{3}$ expression using ${ }^{64} \mathrm{Cu}$-labeled tetrameric RGD peptide. J Nucl Med 2005; 46: 1707-1718.

68. Wu Z, Li ZB, Chen K, Cai W, He L, Chin FT, Li F, Chen X. MicroPET of tumor integrin $\alpha_{\mathrm{v}} \beta_{3}$ expression using ${ }^{18} \mathrm{~F}$-labeled PEGylated tetrameric RGD peptide (18F-FPRGD4). J Nucl Med 2007;48: 1536-1544.

69. Reynolds AR, Hart IR, Watson AR, Welti JC, Silva RG, Robinson SD, Violante GD, Gourlaouen M, Salih M, Jones MC, Jones DT, Saunders G, Kostourou V, Perron-Sierra F, Norman JC, Tucker GC, Hodivala-Dilke KM. Stimulation of tumor growth and angiogenesis by low concentrations of RGD-mimetic integrin inhibitors. Nat Med 2009;15: 392-400. 